\title{
Engineering an efficient and tight D-amino acid-inducible gene expression system in Rhodosporidium/Rhodotorula species
}

\author{
Yanbin Liu, Chong Mei John Koh, Si Te Ngoh and Lianghui Ji
}

\begin{abstract}
Background: Rhodosporidium and Rhodotorula are two genera of oleaginous red yeast with great potential for industrial biotechnology. To date, there is no effective method for inducible expression of proteins and RNAs in these hosts.

Results: We have developed a luciferase gene reporter assay based on a new codon-optimized LUC2 reporter gene (RtLUC2), which is flanked with CAR2 homology arms and can be integrated into the CAR2 locus in the nuclear genome at $>90 \%$ efficiency. We characterized the upstream DNA sequence of a D-amino acid oxidase gene (DAO1) from R. toruloides ATCC 10657 by nested deletions. By comparing the upstream DNA sequences of several putative DAO1 homologs of Basidiomycetous fungi, we identified a conserved DNA motif with a consensus sequence of AGGXXGXAGX ${ }_{11}$ GAXGAXGG within a $0.2 \mathrm{~kb}$ region from the mRNA translation initiation site. Deletion of this motif led to strong mRNA transcription under non-inducing conditions. Interestingly, DAO1 promoter activity was enhanced about fivefold when the $108 \mathrm{bp}$ intron 1 was included in the reporter construct. We identified a conserved CT-rich motif in the intron with a consensus sequence of TYTCCCYCTCCYCCCCACWYCCGA, deletion or point mutations of which drastically reduced promoter strength under both inducing and non-inducing conditions. Additionally, we created a selection marker-free DAO1-null mutant ( $\triangle$ dao1e) which displayed greatly improved inducible gene expression, particularly when both glucose and nitrogen were present in high levels. To avoid adding unwanted peptide to proteins to be expressed, we converted the original translation initiation codon to ATC and re-created a translation initiation codon at the start of exon 2 . This promoter, named $P_{D A O 1-i n ! m l}$, showed very similar luciferase activity to the wild-type promoter upon induction with D-alanine. The inducible system was tunable by adjusting the levels of inducers, carbon source and nitrogen source.
\end{abstract}

Conclusion: The intron 1-containing DAO1 promoters coupled with a DAO1 null mutant makes an efficient and tight D-amino acid-inducible gene expression system in Rhodosporidium and Rhodotorula genera. The system will be a valuable tool for metabolic engineering and enzyme expression in these yeast hosts.

Keywords: D-amino acid oxidase, Oleaginous yeast, Rhodosporidium and Rhodotorula, Inducible gene expression system, Promoter and intron

\section{Background}

Rhodosporidium (teleomorph) or Rhodotorula (anamorph) are phylogenetically highly related yeast and are excellent producers of oil (triacyglyceride) and carotenoid [1, 2]. Dry biomass yield of more than $100 \mathrm{~g} / \mathrm{L}$ can

\footnotetext{
*Correspondence: jilh@tll.org.sg

Biomaterials and Biocatalysts Group, Temasek Life Sciences Laboratory,

1 Research Link, National University of Singapore, Singapore 117604,

Singapore
}

be readily produced within a week with more than $60 \%$ oil content [3-5]. To take advantage of its high metabolic flux and cell mass production, we have been developing it as a synthetic biology platform. Genetic tools reported include Agrobacterium tumefaceins-mediated transformation, constitutive promoter set for gene expression [6-9] and high efficiency gene knockout [7-9]. However, there is no effective means for inducible gene expression to date. 
D-Amino acid oxidase [D-amino acid:oxygen oxidoreductase (deaminating)], DAAO (EC 1.4.3.3) is a FAD-dependent oxidoreductase that catalyzes stereospecifically the oxidative deamination of $\mathrm{D}$-amino acids to $\alpha$-keto acids, ammonia and hydrogen peroxide (Fig. 1). DAAOs have been widely identified, ranging from bacteria, fungi to humans [10]. It is best known for the use in cephalosporin synthesis [11]. DAAO has been used as a marker of peroxisome in many eukaryotic organisms $[12,13]$. $R$. gracilis DAO1 mRNA transcription has been reported to be inducible by $\mathrm{D}$-alanine $(70 \mathrm{mM})$ [14], with the Dao1 protein accumulated to about $0.3 \%$ of total soluble intracellular proteins after induction [15]. To date, the $D A O 1$ gene organization and genetic basis of transcriptional regulation remain unknown.

We report here the cloning and characterization of $R$. toruloides DAO1 and the creation of an efficient D-alanine inducible gene expression system for this industrially important yeast.

\section{Results}

Organization of a D-amino acid oxidase gene DAO1

Previous studies showed that $R$. toruloides ATCC 10657 and R. glutinis ATCC 204091 genes share high sequence homology $[6,16]$. Till now, two Rhodotorula $D A O 1$ sequences have been deposited with GenBank (accession numbers: DM380716 and Z71657) [17]. BLASTn search of $R$. glutinis ATCC 204091 genome identified a homologous gene (EGU13479.1) in scaffold $\# 23.5^{\prime}$ and $3^{\prime}$ RACE using total RNA of $R$. toruloides ATCC 10657 as template yielded a cDNA fragment of approximately $0.5 \mathrm{~kb}$ each (data not shown). The fulllength cDNA was amplified by RT-PCR using oligonucleotide pair Rt332f/Rt333r (Table 1) (data not shown). The full-length cDNA (1183 nt) was predicted to encode an ORF of 368 aa with 29 nt $5^{\prime}$ UTR (untranslated region) and $47 \mathrm{nt} 3^{\prime}$ UTR. As expected, the ORF is GC-rich with a GC content of $63.0 \%$. The sequence context (ACGCCATGC) of the putative translation initiation codon fits quiet well with the Kozak consensus of eukaryotes (CC(A/G)CCATGG) [18]. Comparison between the cDNA and genomic sequences revealed 6 exons separated by 5 introns (Fig. 2; Additional files 1,2). The DAO1 ORF utilizes 58 codons (Additional file 4). Similar to GPD1 [6], codon utilization showed strong preference for cytosine at the Wobble position with the exceptions of alanine, arginine, serine and threonine, in which guanine was preferred. The DAO1 mRNA contains no canonical polyadenylation signal (AATAAA) in the $3^{\prime}$ UTR. Similar to GPD1, a short region with TG repeats can be found 28 nt upstream of the polyadenylation site (Additional file 1). DAO1 homologs of $R$. toruloides strain ATCC 10657 and ATCC 204091 differed by only two nucleotides in the coding region, both being silent mutations (encoding residue $\mathrm{I}_{186}$ and $\mathrm{A}_{296}$, respectively) (Additional file 1). The Dao1 enzyme was predicted to contain a highly conserved sequence motif (GXGXXG, where "X" indicates any amino acid) as required for FAD coenzyme binding [19]; amino acid residues that are critical for catalytic reaction $\left(\mathrm{Y}_{223}, \mathrm{Y}_{238}\right.$ and $\left.\mathrm{R}_{285}\right)$ [20]; and a C-terminal SKL-tripeptide as the peroxisomal targeting signal (PTS1) [21]; Additional file 1).

BLAST search using $R$. toruloides DAO1 as query identified several DAO1 homologs from Pucciniomycotina and Ustilagiomycotina subphyla (Additional file 2A). These genes were predicted to contain 2-7 introns although the Ustilago maydis homolog appeared intronless. Interestingly, members in the Ustilagiomycotina subphyla divide Pucciniomycotina into two subgroups, one consisting of Rhodosporidium, Rhodotorula and Sporobolomyces and the other consisting of Puccinia and Melampsora (Additional file 2B).

\section{Regulation of $D A O 1$ mRNA transcription}

We compared DAO1 mRNA levels in media supplemented with D-alanine and L-alanine by qRT-PCR. As expected, the mRNA transcripts were negligible when cells were cultured in minimal medium (MinABs) supplemented with L-alanine or ammonium sulfate as the

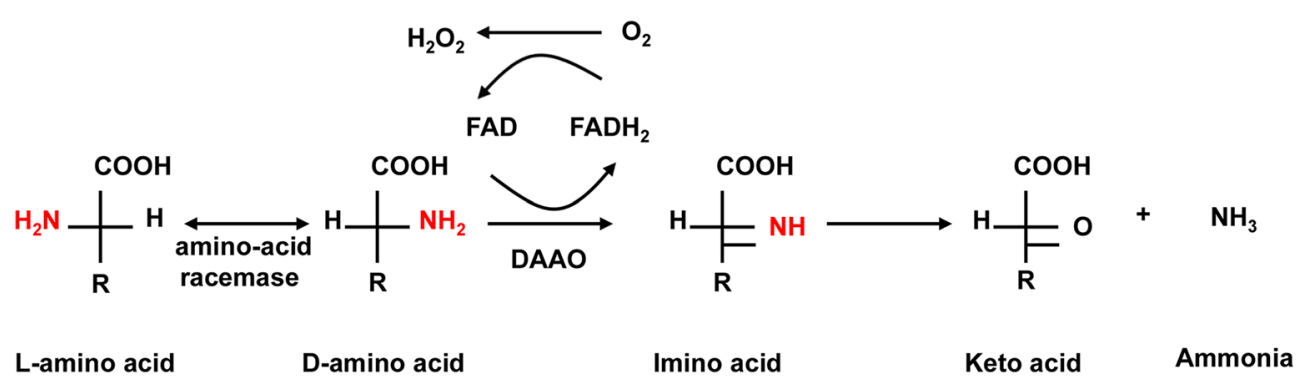

Fig. 1 Reactions catalyzed by D-amino acid oxidase. Imino acid is believed be hydrolyzed non-enzymatically to the corresponding keto acid and ammonia. L-amino acids may be converted to $\mathrm{D}$-amino acids by L-amino acid racemase 
Table 1 Oligonucleotides used

\begin{tabular}{|c|c|c|}
\hline Name & Sequence (restriction enzyme site) $)^{a}$ & PCR target \\
\hline DAO1U1 & 5'-CACTTTGCTTGTCGAGGACCGTC-3' & $5^{\prime}$ RACE \\
\hline DAO1L1 & 5'-ACGACCAGGTGGCGAAGTGATCT-3' & $3^{\prime}$ RACE \\
\hline Rt332f & 5'-GCTTGTACTGCTCGAACGAC-3' & CDNA \\
\hline Rt333r & 5'-CTGGTGAAATGCCCCAATAC-3' & CDNA \\
\hline Rt290Sf & 5'-TTTactagtCTTCCCGGTCTCGTATCGAG-3' (Spel) & $P_{D A O 1-i n 1} 2.2 \mathrm{~kb}$ \\
\hline Rt315S & 5'-TTTactagtACTCCGCAATCTGCAGAGAC-3' (Spel) & $P_{D A O I m 2-i n 1} 1.7 \mathrm{~kb}$ \\
\hline Rt314S & 5'-TTTactagtCATGGTCTGATCGCTTGTGTG-3' (Spel) & $P_{D A O I m 3-i n 1} 1.2 \mathrm{~kb}$ \\
\hline Rt120S & 5'-TTTactagtGTGGCAGGTGTGCGTG-3' (Spel) & $P_{D A O 1 m 4-i n 1} 1.0 \mathrm{~kb}$ \\
\hline Rt313S & 5'-TTTactagtCGTTCGTGGGCTCAAGGAAG-3' (Spel) & $P_{D A O 1 m 5-i n 1} 0.7 \mathrm{~kb}$ \\
\hline Rt117S & 5'-TTTactagtCGACGACGGGAAGCTTCG-3' (Spel) & $P_{D A O I m 6-i n 1} 0.4 \mathrm{~kb}$ \\
\hline $\mathrm{Rt} 287 \mathrm{Nr}$ & 5'-TTTccatggCAATCACTGTATAATCAAGAGCTG-3' (Ncol) & $P_{D A O 1-i n 1}$ reverse \\
\hline Rt309Nr & 5'-TTTccatggCGTCGTTCGAGCAG-3' (Spel) & $P_{D A O 1}$ reverse \\
\hline Rt311 & 5'-GAAGCTTCGGCACGAGCATG-3' & $P_{D A O I m 5-i n 1 m 1}$ \\
\hline Rt312 & 5'-ACAGTCATGCTCGTGCCGAAGCTTCGCAACCGCTCATCAGTACAC-3' & $P_{D A O 1 m 5-i n 1 m 1}$ \\
\hline SFGFPSEQ & 5'-GGACAAACCACAACTAGAATGCAG & $\mathrm{P}_{D A O I m 5-\operatorname{in} 1 \mathrm{~m} 1}$ \\
\hline 35STer & 5'-AAAGCATGCTAATTCGGGGGATCTGGAT & $P_{D A O I m 5-i n 1 m 1}$ \\
\hline Rt288f & 5'-GTAGGTTACGCCGATCGAGTTG-3' & DAO1 Probe \\
\hline Rt289r & 5'-GCTCGACCAACTGCTCTCTTTC-3' & DAO1 Probe \\
\hline Rt327r & 5'-GGCGTCGTTCGAGCAGTAC-3' & $\mathrm{P}_{D A O I m 5-\operatorname{in} 1 \mathrm{~m} 2}$ \\
\hline Rt328f & 5'-CTGCTTGTACTGCTCGAACGACGCCATCCATTCACAGAAGCGCGTCGT-3' & $P_{D A O I m 5-i n 1 m 2}$ \\
\hline Rt329r & 5'-GACGCACCGCCTGATCCGAG-3' & $\begin{array}{l}P_{D A O I m 5-i n 1 m 2} \\
P_{D A O I m 5-i n 1 m 3}\end{array}$ \\
\hline Rt330f & 5'-TTGTCCTCGGATCAGGCGGTGCGTCTTTAAATATAATAAAAAAAAAAGACAGTTCTCGAGGAGGAGTAC-3' & $P_{D A O I m 5-i n 1 m 2}$ \\
\hline Rt331f & 5'-TTGTCCTCGGATCAGGCGGTGCGTC(24 mer deletion)CAGTTCTCGAGGAGGAGTAC-3' & $\mathrm{P}_{\text {DAOIm5-inim3 }}$ \\
\hline Rt334f & 5'-TTGTCCTCGGATCAGGCGGTGCGTCTTTCAATCTCCTCCCCACACCCGACAGTTCTCGAGGAGGAGTAC-3' & $\mathrm{P}_{D A O 1 m 5-\operatorname{in} 1 \mathrm{~m} 4}$ \\
\hline Rt335f & 5'-TTGTCCTCGGATCAGGCGGTGCGTCTTTCCCTCTAATCCCCACACCCGACAGTTCTCGAGGAGGAGTAC-3' & $P_{D A O 1 m 5-\operatorname{in} 1 m 5}$ \\
\hline Rt336f & 5'-TTGTCCTCGGATCAGGCGGTGCGTCTTTCCCTCTCCTCAACACACCCGACAGTTCTCGAGGAGGAGTAC-3' & $\mathrm{P}_{\text {DAOIm5-in } 1 m 6}$ \\
\hline Rt337f & 5'-TTGTCCTCGGATCAGGCGGTGCGTCTTTCCCTCTCCTCCCCGCACCCGACAGTTCTCGAGGAGGAGTAC-3' & $\mathrm{P}_{\text {DAOIm5-in } 1 m 7}$ \\
\hline Rt338f & 5'-TTGTCCTCGGATCAGGCGGTGCGTCTTTCCCTCTCCTCCCCACACAAGACAGTTCTCGAGGAGGAGTAC-3' & $P_{D A O I m 5-i n 1 m 8}$ \\
\hline LUC2U & 5'-GAAGTACTCGGCGTAGGTG-3' & $\begin{array}{l}\text { In RtLUC2, for amplification of } \\
P_{D A O 1 m 1-\text { in } 1 m 1 \sim} P_{D A O I m 5-\text { in } 1 m 8}\end{array}$ \\
\hline DAO1f & 5'-CTTCGTGCTAACCAAGCTCGT-3' & Probe and colony PCR of DAO1 \\
\hline DAO1r & 5'-GTCTCAGGGTTGACGGACAAG-3' & Probe and colony PCR of DAO1 \\
\hline qDAO1f & 5'-TCAAACCGTCCTCGTCAAGTC-3' & qPCR of DAO1 \\
\hline qDAO1r & 5'-GTTGACGGACAAGTCCCAATC-3' & qPCR of DAO1 \\
\hline qACT1f & 5'-TACCCAACTTGTCCCAACCTG-3' & $\mathrm{qPCR}$ of $A C T 1$, reference gene \\
\hline qACT1r & 5'-CTCGTCTCCATCACCATCCTC-3' & $\mathrm{qPCR}$ of $A C T 1$, reference gene \\
\hline DAO1L-Sf & 5'-AAAgagctcGACTCGTTGGGCAAAGTGAAG-3' (Sacl) & Deletion of $D A O 1$ \\
\hline $\mathrm{DAO1L-Br}$ & 5'-AAAggatccGGAAGCGCACAAAGTCAATTC-3' (BamHI) & Deletion of $D A O 1$ \\
\hline DAO1R-Hf & 5'-TTTaagcttCAAAGGAGAAGGAGGTGACA-3' (HindIII) & Deletion of $D A O 1$ \\
\hline DAO1R-Str & 5'-TTTaggcctGTCTATTTGCGGTGGAATGGA-3' (Stul) & Deletion of $D A O 1$ \\
\hline
\end{tabular}

a Sequences in lowercase and italics denote the recognition site for the restriction enzyme used (marked in brackets)

sole nitrogen source (Fig. 3a). After 3 and $6 \mathrm{~h}$ of induction with $70 \mathrm{mM}$ D-alanine, the native DAO1 mRNA level was 12 and 18 folds higher than that of cells cultured with $70 \mathrm{mM}$ L-alanine, respectively. Transcription was induced $\sim 100$ folds if both glucose and ammonium sulfate were omitted in the culture medium. These results suggest that the induction of $D A O 1$ expression is specific to D-alanine and carbon source (glucose) and inorganic nitrogen source strongly suppress mRNA transcription although glycerol appeared to be slightly stimulatory. In 


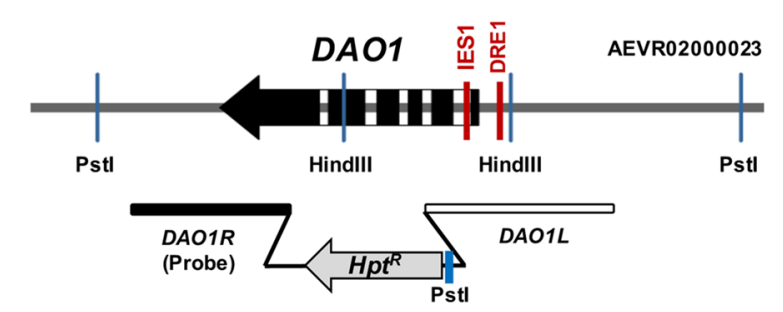

Fig. 2 Organization of $D A O 1$ gene. a Schematic diagram of RtDAO1 gene. Probe $2(D A O 1 R)$ were used for verification of DAO1 gene deletion in Southern blot analysis. DRE1 and IES1 indicate the position of the D-amino acid responsive element 1 and intronic enhancing element, respectively. $\mathrm{Hpt}^{\mathrm{R}}$ : hygromycin resistance cassette. DAO1R and DAO1L: homology arms used for DAO1 knockout

addition, $D A O 1$ transcription was found depressed by several stress stimuli (Fig. 3b).

\section{Bioinformatic analyses of cis-acting elements in DAO1 promoter}

Sequence analysis of $D A O 1$ upstream region revealed one putative CAAT box (CCAAT) at -645 from the translational start codon. No TATA box could be found near the transcriptional start point (tsp). However, a 15-nt pyrimidine-rich region ( -44 to -30 ) (ct box) is located immediately upstream of tsp (Additional file 1).

Scanning the $\sim 1.0 \mathrm{~kb} D A O 1$ upstream sequences of several Rhodosporidium and Rhodotorula strains at YEASTRACT (Yeast Search for Transcriptional Regulators And Consensus Tracking, http://www.yeastract.com/) [22] identified several potential transcription factor binding sites with functions in stress response (Gis1p, Hac1p, Hsf1p, Mot3p, Msn2p/4p, Stb5p and Xbp1p), carbon source catabolism (Cat8p/Sip4p, Gcr1p, Nrg1p, Rgt1p), DNA synthesis (Mbp1p) and transcription repression (Ash1p) (Fig. 4a). In addition, analysis of upstream sequences $(1.0 \mathrm{~kb})$ of $D A O 1$ gene from several basidiomycetous fungi at the MEME server (http://meme. nbcr.net/meme/) identified three conserved sequence motifs (Fig. 4b). Motif 1 has a consensus sequence of

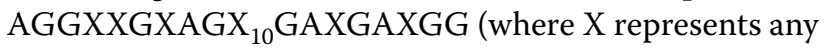
nucleotide) and is the most conserved amongst Rhodsporidium and Rhodotorula species (Fig. 4b, c).

\section{Functional dissection of $D A O 1$ promoter using luciferase reporter}

Reporter assays were performed to define the minimal DNA sequence required to drive the $\mathrm{D}$-amino acid inducible gene expression. DAO1 upstream DNA fragments consisting of a series of nested deletions and site-specific mutations were used for gene reporter assay. Previously, a codon-adapted green fluorescent protein-encoding gene (RtGFP) was used for reporter assay in $R$. toruloides using
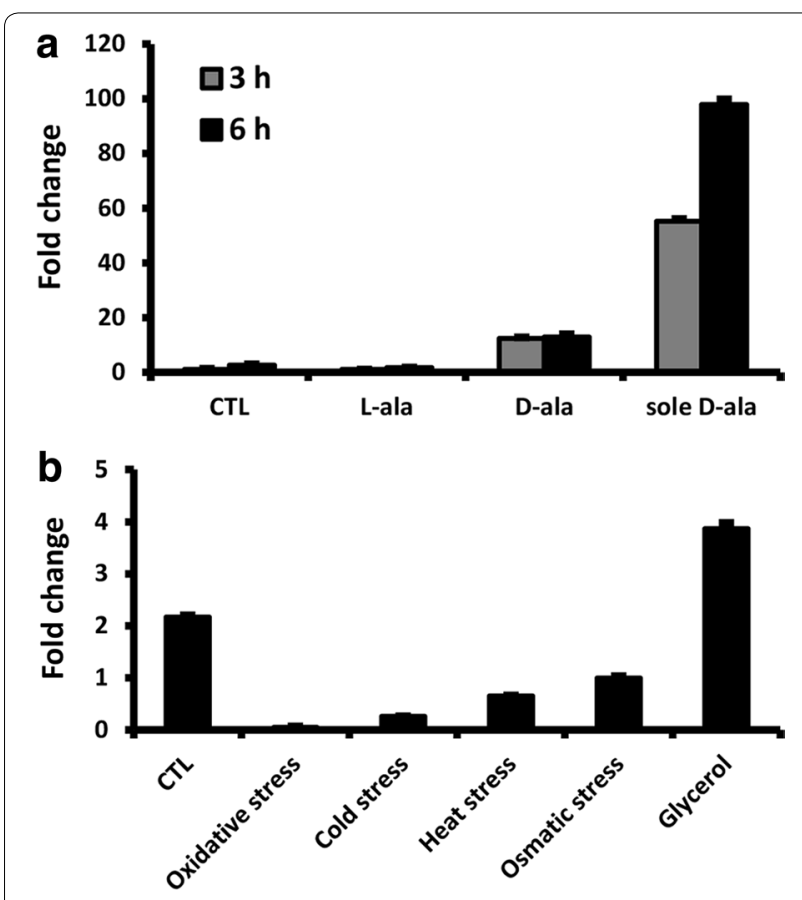

Fig. 3 Transcription of native DAO1 mRNA in R. toruloides. a Relative mRNA levels at 3rd and 6th hour when cells were cultured in MinABs medium supplemented with D- or L-alanine (70 mM). Carbon and nitrogen sources used: CTL_-glucose and ammonium sulfate; L-ala-glucose and L-alanine; D-ala-glucose and D-alanine; sole D-ala-D-alanine only. The mRNA level at 6th hour in medium using D-alanine as the sole carbon and nitrogen source is set as $100 \%$. b Relative mRNA in cells cultured under various stress for $6 \mathrm{~h}$. CTL: YPD broth at $28{ }^{\circ} \mathrm{C}$; oxidative stress: YPD broth supplemented with $1 \%$ $\mathrm{H}_{2} \mathrm{O}_{2}$ (W/v) and cultured at $28^{\circ} \mathrm{C}$; cold stress: YPD broth at $4{ }^{\circ} \mathrm{C}$; heat stress: YPD broth at $37^{\circ} \mathrm{C}$; osmatic stress: YPD broth supplemented with $1 \mathrm{M} \mathrm{KCl}$ and cultured at $28^{\circ} \mathrm{C}$; glycerol: YPG broth (carbon source of glucose in YPD replaced with the same concentration of glycerol) and cultured at $28^{\circ} \mathrm{C}$

a large pool of randomly integrated T-DNA transformants [6]. Although effective, we found that the RtGFP reporter is prone to background interference and showed large batch-to-batch variations (unpublished data). To overcome these problems, we used a codon-optimized firefly luciferase gene, RtLUC2 (GenBank accession number ACH53166), to compare the strength of various $D A O 1$ promoter fragments. Luciferase reporter cassettes were integrated at the $C A R 2$ locus using the $\Delta \mathrm{ku} 70 \mathrm{e}$ strain, which allows highly efficient site-specific integration of the reporter cassette [7]. As CAR2 encodes a bifunctional enzyme phytoene synthase and lycopene cyclase that are essential for the biosynthesis of carotenoids in $R$. toruloides, site-specific integration at the locus lead to albino colony phenotype (Fig. 5) [7].

Interestingly, inclusion of intron 1 in the reporter increased the promoter activity about fivefold, and this was independent of the presence of inducer D-alanine 
a

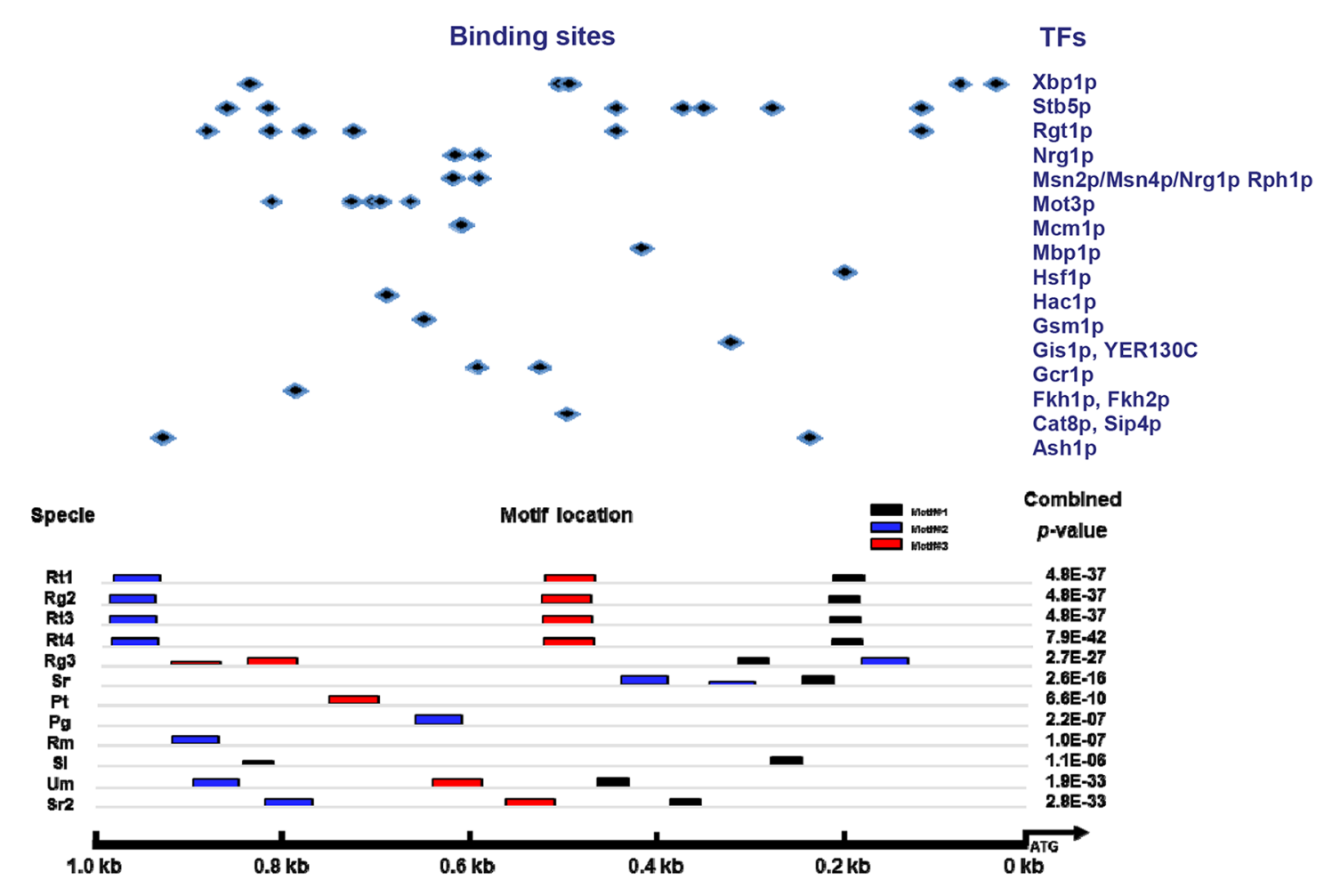

b

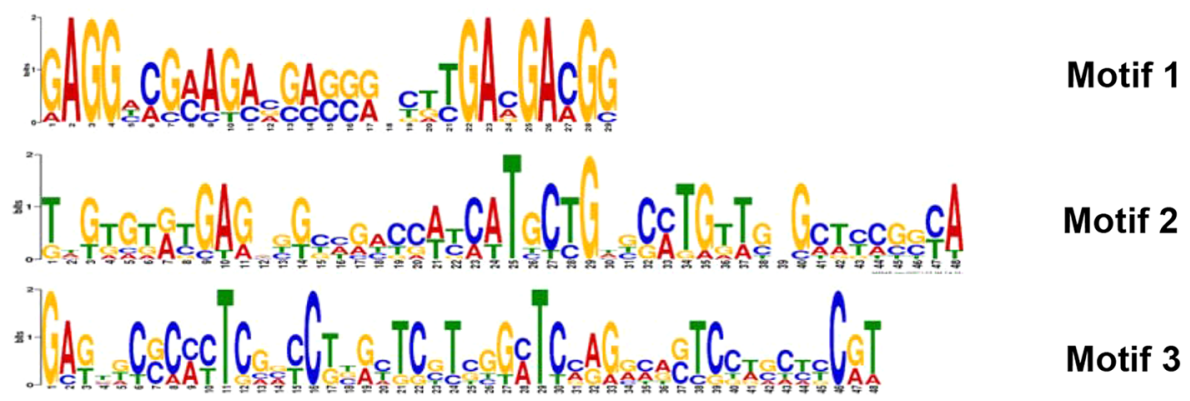

C

$\begin{array}{lrr}\text { Name } & \text { Start } & p \text {-value } \\ \text { Rg3 } & -307 & 9.8 \mathrm{E}-14 \\ \mathrm{Um} & -468 & 1.5 \mathrm{E}-13 \\ \mathrm{Sr2} & -391 & 2.1 \mathrm{E}-13 \\ \mathrm{Sr} & -252 & 2.4 \mathrm{E}-12 \\ \mathrm{Rg} 2 & -222 & 4.2 \mathrm{E}-12 \\ \mathrm{Rt1} & -219 & 1.7 \mathrm{E}-11 \\ \text { Sl } & -285 & 1.4 \mathrm{E}-10\end{array}$

Sequence

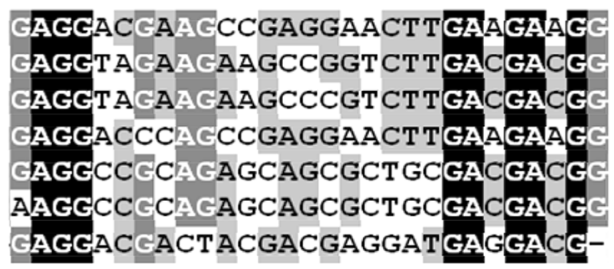

AGG--G-AG-----------GA-GA-GG

Fig. 4 Analysis of upstream sequences of DAO1 in Pucciniomycotina. a Localization of conserved DNA motifs in 1.0 kb upstream regions. Different transcription factor recognition sites were predicted based on the yeast transcription factor database YEASTRACT (http://www.yeastract.com). b Nucleotide sequence logos of the 3 DNA motifs indicated above. c Alignment motif 1 sequences of Pucciniomycotina. Abbreviations: Rt1 R. toruloides ATCC 10657, Rt3 R. toruloides MTCC 457, Rt4 R. toruloides NP11, Rg2 R. glutinis ATCC 204091, Rg3 R. graminis WP1, Sr S. roseus, Pt P. tritartic, Pg P. graminis, Rm R. minuta; SI S. linerdae, Um U. maydis, Sr2 S. reilianum 
a
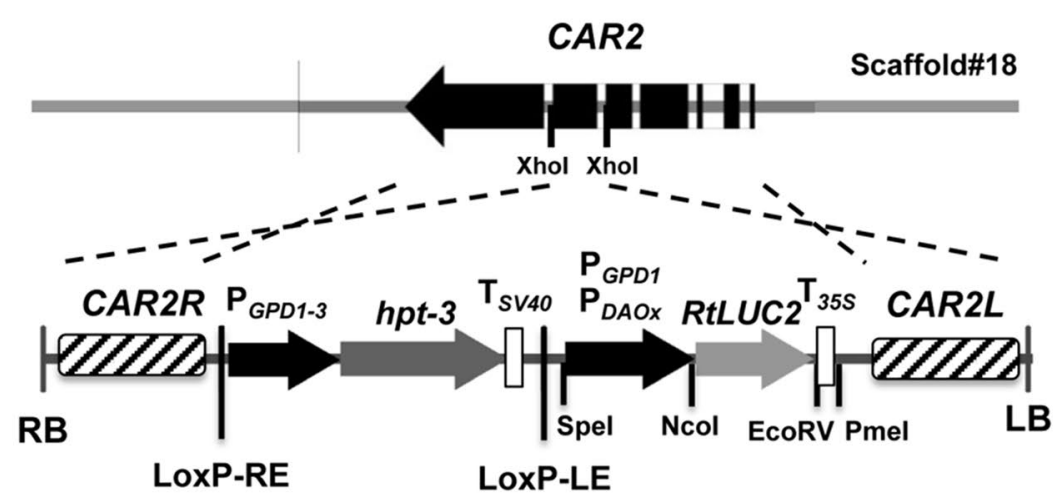

pKCL2/pKCLDx

b

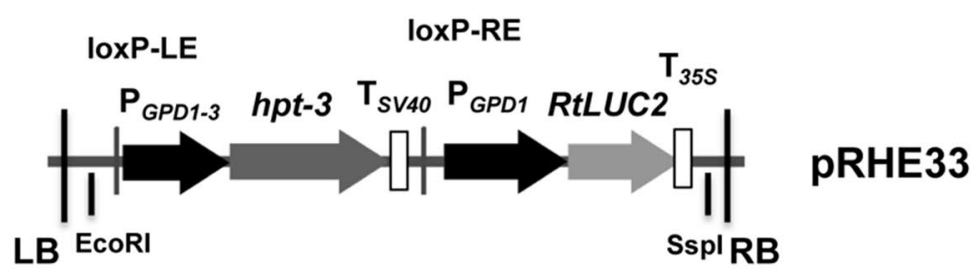

C

-50 caactgetct ctttcgctct tGCTGCTGCT TGTACTGCTC GAACGACGCC ct box $\uparrow^{t s p}$

1 ATGCATTCAC AGAAGCGCGT CGTTGTCCTC GGATCAGGCG gtgcgtcttt $\begin{array}{llllllllllllllllll}\text { P1 } & \text { M } & \text { H } & \text { S } & Q & \text { K } & \text { R } & \text { V } & \text { V } & \text { V } & \text { L } & \text { G } & \text { S } & \text { G }\end{array}$

51 ccctctcctc cccacaccog acagttctcg aggaggagta cagcagcgag IES1 intron 1

101 cgaggctgcc gagggggatc tgggttgacg cagctcttga ttatacagTG P14 CCATGG intron 1 V 151 ATtGGCCTGA GCAGCGCCCT CATCCTCGCT CGGAAGGGCT ACAGCGTGCA $\begin{array}{llllllllllllllllll}\text { P15 } & \text { I } & G & \text { L } & \text { S } & \text { S } & \text { A } & \text { L } & \text { I } & \text { L } & \text { A } & \text { R } & \text { K } & \text { G } & \text { Y } & \text { S } & \text { V } & \text { H }\end{array}$

d

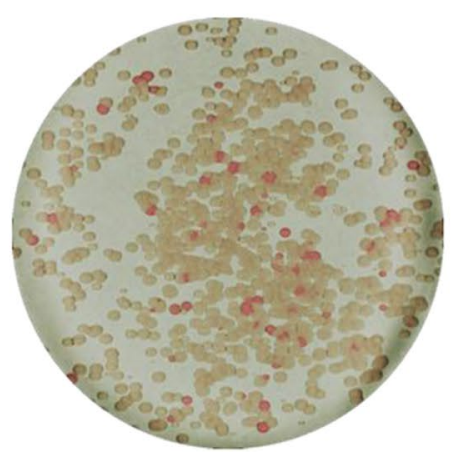


(See figure on previous page.)

Fig. 5 RtLUC2 reporter system. a Schematic diagram of DAO1 gene structure and the T-DNA regions of reporter plasmid pKCL2 and pKCLDx. RB and LB: right and left borders Agrobacterium tumefaceins T-DNA; CAR2L and CAR2R: left and right homology arms of CAR2 locus that were used for locusdirected integration of RtLUC2 reporter constructs; $P_{G P D 1-3:}$ GPD1 promoter of Rhodotorula graminis WP1; hpt-3: codon-optimized hygromycin resist-

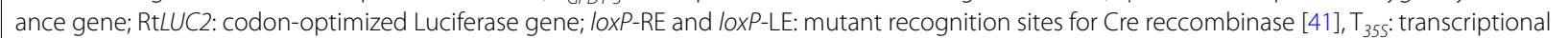
terminator of Cauliflower mosaic virus gene 35S; DAOx indicates various DAO1 promoter fragments in the reporters; $\mathbf{b}$ T-DNA regions of binary vector pRHE33. c Important features of the DAO1 mRNA transcription. tsp transcriptional start point; Terminal sequence of $\mathrm{P}_{D A O 1-\text { in } 1}$ promoters are shown in the box. d Typical colony color phenotypes of pKCL2/pKCLDx transformants

(Fig. 6a, b, compare $\mathrm{P}_{D A O 1}$ and $\mathrm{P}_{D A O 1-i n 1}$ ). Deletion of the conserved motif 1 (DRE1) had little effect on the promoter strength when cultured under inducing conditions. In contrast, motif 1 deletion resulted in a 6.7fold increase in promoter activity when cultured under non-inducing condition using L-alanine as sole nitrogen and carbon source (Fig. 6a, b, compare $\mathrm{P}_{D A O 1 m 1 \text {-in1 }}$ and $\left.\mathrm{P}_{D A O 1 \text {-in1 } 1}\right)$. This suggests motif 1 repressed DAO1 expression under the non-inducing condition. Thus, we termed motif 1 as "D-amino acid responsive element 1 (DRE1)". Notably, DAO1 promoter drove stronger Rt $L u c 2$ expression than GPD1 [6] did under non-induction conditions (Fig. 6b). An additional series of nested deletions of the $2.2 \mathrm{~kb} D A O 1$-in1 promoter revealed that the 0.7 and $0.4 \mathrm{~kb}$ fragments were comparable to the full-length $2.2 \mathrm{~kb}$ promoter in terms of strength and stereospecificity (Fig. 6c).

As intron 1 of $D A O 1$ gene strongly enhanced the promoter activity, we sought to identify the cis-acting element involved. Analysis of the DAO1 intron 1 sequences of several Rhodosporidium/Rhodotorula species at MEME server identified a conserved 24-bp CT-rich motif (Fig. 7a) with a consensus sequence of $\mathrm{T}(\mathrm{T} / \mathrm{C})$ $\mathrm{TCCC}(\mathrm{T} / \mathrm{C}) \mathrm{CTCC}(\mathrm{T} / \mathrm{C}) \operatorname{CCCCAC}(\mathrm{A} / \mathrm{T})(\mathrm{C} / \mathrm{T}) \mathrm{CCGA}$, which we named as intronic enhancer sequence 1 (IES1) (Fig. 7b). To demonstrate the function of IES1, seven mutants containing complete deletion or 1-2 nt mutations in IES1 were made in the $0.7 \mathrm{~kb} D A O 1 m 5$-in1 promoter (Figs. 6, 7c). All above mutant promoters showed severely reduced strength when either D or L-alanine was used as the sole carbon and nitrogen source (Fig. 7d, e). These results support our assumption that IES1 is a general transcriptional enhancing element. Because the inclusion of intron 1 in the promoter added a 16-aa peptide to the $\mathrm{N}$-termini of proteins expressed, we sought to create an improved promoter that yields clean protein translation, with no fusion of foreign peptide. We mutated the original translation initiation codon ACGCCATGC located in exon 1 to ACGCCATCC and re-created a new translation start codon (ATG) by changing the "TTGGCCTGA" sequence at the start of exon 2 to "TTGCCATGG", which contains an NcoI site that allows

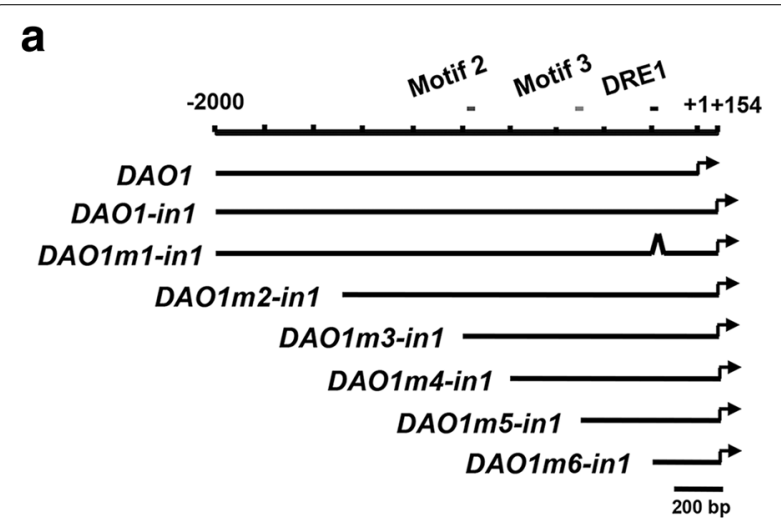

b

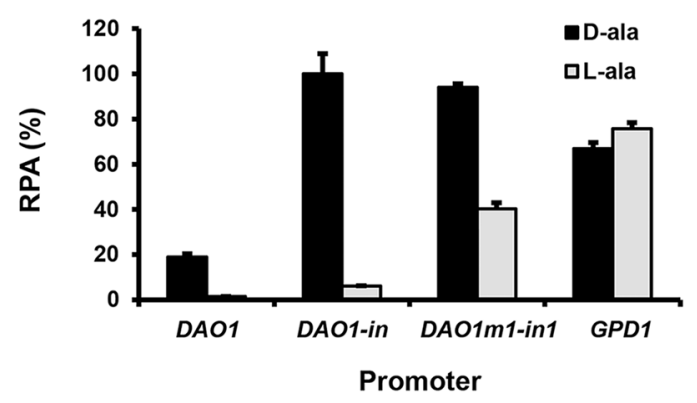

C

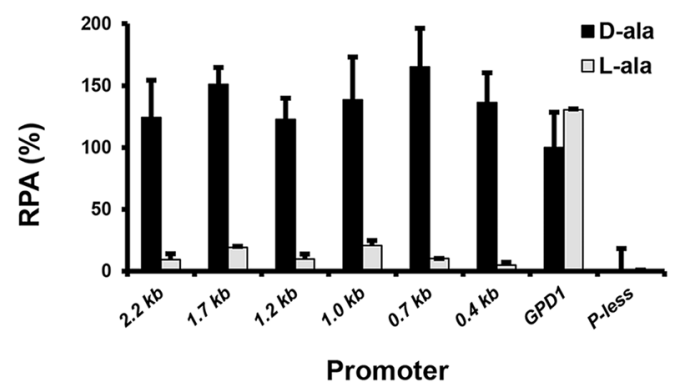

Fig. 6 Functional dissection of $D A O 1$ promoter. a Schematic diagram of serial deletions of DAO1 promoter knocked in at CAR2 locus. $\mathbf{b}$ Effect of motif 1 and intron 1. Promoter activities were assayed with luciferase kit using cells cultured for $21 \mathrm{~h}$ in MinABs medium supplemented with D-alanine or L-alanine. c Relative promoter activities (RPA) of various deletions. GPD1 promoter refers to the 795-bp promoter of glyceraldehyde-3-phosphate dehydrogenase gene. P-less promoter-less background control 
seamless fusion of coding sequence of interest with the promoter. The promoter was named $\mathrm{P}_{\text {DAO1-in1m1. Results }}$ confirmed that the modifications had little effect on the promoter strength and selectivity (Figs. 5c, 7d).
Medium optimization for $\mathrm{D}$-amino acid inducible gene expression

With the creation of luciferase reporter system, factors that influence gene expression could be identified.

a

\begin{tabular}{|c|c|c|c|c|}
\hline Vame & Strand & Start & $p$-value & Sites \\
\hline Rt4 & + & 9 & $2.90 E-30$ & УТСТССТССССАСА \\
\hline Rt3 & + & 9 & 2.90 & GTGCGTCT TTTCCСTCTCCTCCCCACACCC $₫ A$ CAGTCCTCGA \\
\hline $\operatorname{Rg} 2$ & + & 8 & 2.01 & 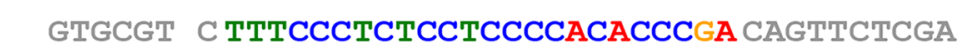 \\
\hline $\mathrm{Rg} 3$ & + & 21 & $6.47 E-19$ & СССТСАСАС ТСТСССССТСССССССАСТTCC $\mathrm{A}$ \\
\hline
\end{tabular}

b

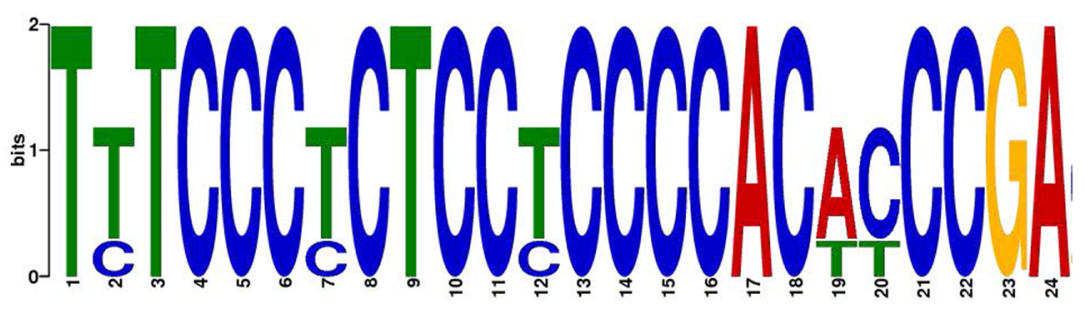

C

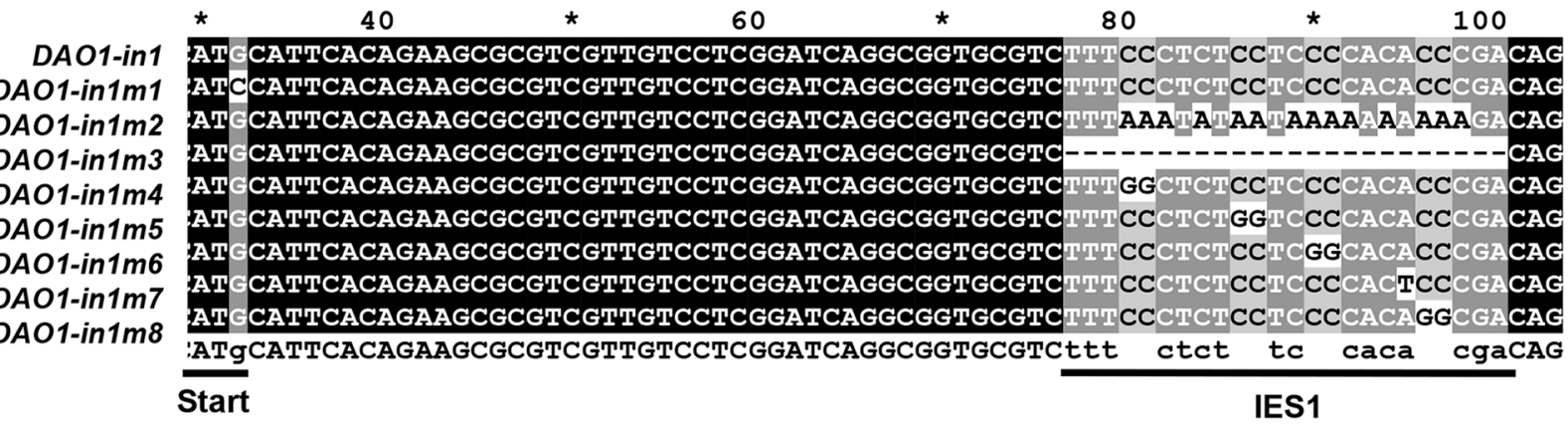

d
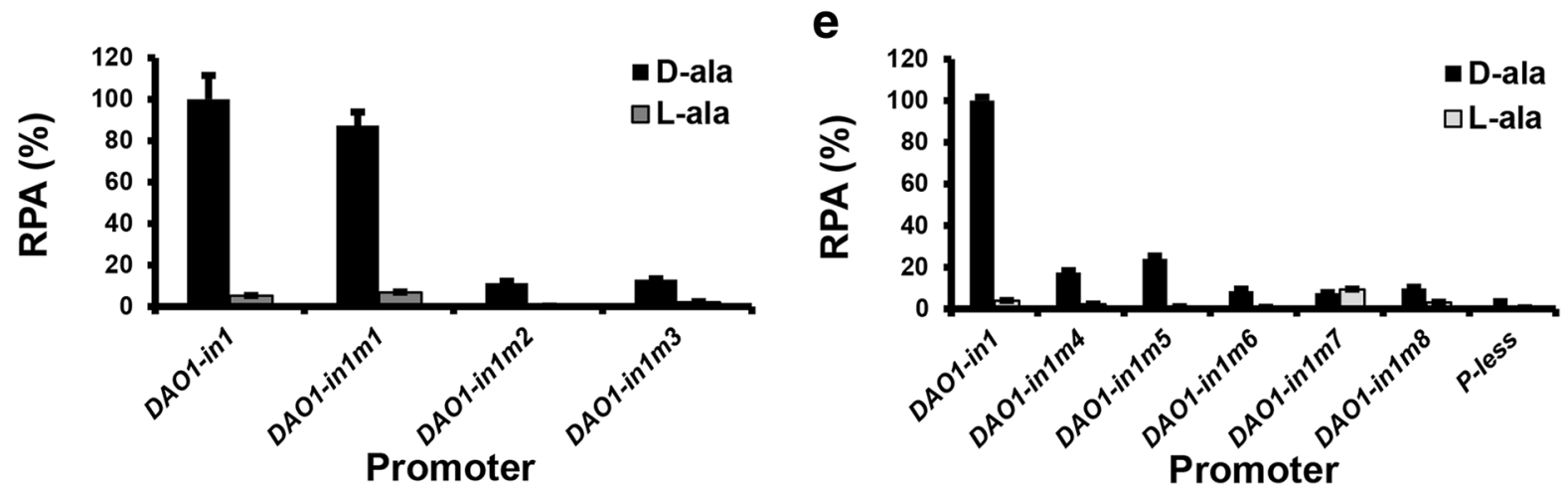

Fig. 7 Functional characterization of intron 1 sequences of DAO1. a Alignment of the conserved DNA motifs in DAO1 intron 1 of Rhodospordium and Rhodotorula species. b Nucleotide sequence logos of the DNA motifs shown above. Rt3 R. toruloides MTCC 457, Rt4 R. toruloides NP11, Rg2 R. glutinis ATCC 204091, Rg3 R. graminis WP1. c Sequences of various IES1 mutants used in P PAO1-in1m2 q. Translational start site and IES1 motif are underlined. d, e Relative strength of DAO1 promoter mutants shown in c 
We chose strain KCLD2, which contains a copy of the 2.2-kb DAO1-in1 promoter linked to Rt $L U C 2$ inserted into the CAR2 locus, for medium optimization. Cells were cultured in MinABs medium supplemented with glucose and/or ammonium sulfate. The strongest luciferase expression was observed when $70 \mathrm{mM}$ D-alanine was used as the sole carbon and nitrogen sources. L-alanine was a potent antagonist. An equal concentration of L-alanine reduced luciferase activity about fivefold at $21 \mathrm{~h}$ after induction when induction was made with $70 \mathrm{mM}$ D-alanine (Fig. 8a). Ammonium sulfate (70 mM) alone had little effect while glucose at $10 \mathrm{~g} / \mathrm{L}$ reduced the expression by half. Supplementation of both glucose $(10 \mathrm{~g} / \mathrm{L})$ and ammonium sulfate $(70 \mathrm{mM})$ led to a drastic reduction of promoter activity. D-alanine as low as $20 \mathrm{mM}$ was effective in inducing the expression of luciferase although increasing the concentration further enhanced the expression (Fig. 8b). Glucose (10-100 g/L) and ammonium sulfate (5-50 mM) supplementation resulted in only marginal reduction of promoter activity (Fig. 8c, d).

The luciferase activity appeared to display two peaks, at about 18 and $44 \mathrm{~h}$ after induction (Fig. 8e). D-threonine, $\mathrm{D}$-serine and $\mathrm{D}$-valine were similarly effective while D-proline, D-leucine, D-phenylalanine, D-tryptophan and D-methionine were significantly less effective (Fig. 8f) [23].

\section{DAO1 deletion further improved the inducible gene expression system}

As Dao1 degrades D-amino acid inducers over time, we sought to test if $D A O 1$ mutation would improve the inducibility and stability of the expression system. We created a $D A O 1$ knockout mutant $(\triangle$ dao1) in the $R$. toruloides $\Delta \mathrm{ku} 70 \mathrm{e}$ strain, in which the hygromycin selection cassette was removed by activating the Cre/loxP recombination system pre-integrated in the genome (our unpublished data). Two clean knockout mutants ( $\Delta$ dao1) were obtained and verified by Southern blotting (Fig. 9a). As expected, DAO1 null mutant showed noticeable growth defect when cultured in medium with D-alanine as the sole carbon source. However, the defect was much milder when cultured in medium with L-alanine as the sole carbon source (Fig. 9b). The $\Delta$ dao1 strain grew essentially like wild-type in complete media such as YPD and Y4 medium (data not shown). Similarly, we deleted the selection cassette by activating the Cre/loxP system and the resultant strain $(\Delta$ daole $)$ showed significantly higher luciferase activity than wildtype when the $\mathrm{P}_{D A O 1-}$ in $1:$ Rt $L U C 2$ cassette was inserted into the CAR2 locus (Fig. 9c). Mostly importantly, the $2.2 \mathrm{~kb} D A O 1$-in 1 promoter showed much higher luciferase activity in $\Delta$ daole than wildtype background in several conditions tested
(Fig. 9c). In media with high concentrations of both glucose and ammonium sulfate, DAO1 deletion increased the reporter gene expression 17 folds when induced with $70 \mathrm{mM}$ D-amino acid (Fig. 9c).

To demonstrate the application of $D A O 1$-in1 promoter in lipid production stage, strains KCLD2 and KCLD21 (with $\mathrm{P}_{\text {DAO1-in1 }}:$ Rt LUC2 integrated at the CAR2 locus in WT and $\triangle$ daole, respectively), were cultured in the lipid accumulation medium Y4 that allows high cell density culture and high oil accumulation [24]. While the promoter showed deceasing activity over the 4-day culture period in wildtype, it showed a steady increase of activity in $\Delta$ daole background (Fig. 9d), which appeared to be concomitant with carbon and nitrogen depletion (Additional file $3 \mathrm{~A}$ and $3 \mathrm{~B}$ ). Interestingly, gene expression was repressible with $\mathrm{D}$-alanine in $\Delta$ daole background during the initial 2-day culture. Importantly, effective induction could be achieved with $\mathrm{D}$-alanine in levels as low as $1 \mathrm{mM}$. These results indicate that the DAO1-in 1 promoter is a useful tool for inducible expression of genes under lipid production conditions, particularly when a DAO1 null mutant is used. The strength of gene expression could be tuned by adjusting the levels of inducer, carbon source and nitrogen source.

\section{Discussion}

Promoters are key element for gene expression systems, either for modulation of biosynthetic pathways or production of recombinant proteins. Carbon source and nitrogen source regulated promoters have been widely used in fungi [25-27], for example, galactose-inducible promoters have been very successful in Saccharomyces cerevisiae [28]. While putative GAL1, GAL4, GAL7 and GAL10 homologs could be found in Rhodosporidium and Rhodotorula genomes, none of the promoters were effectively induced by galactose (data not shown).

The lack of an effective inducible gene expression system had been a major hurdle in making Rhodosporidium and Rhodotorula a competitive host for metabolic engineering and synthetic biology. This report specifically addresses this issue. Luciferase gene reporter assays of systemically truncated and site-specific mutations of DAO1 upstream DNA fragments allowed us to engineer a D-amino acid inducible promoter that is robust and simple to use. The promoter can be as small as $0.4 \mathrm{~kb}$ and, after inactivating the original translation initiation codon in exon 1 and re-creating a new ATG is exon 2. Based on the ribosome scanning model [29], protein translation could be initiated only at TTGCCATGG in the mutant promoters, such as $\mathrm{P}_{D A O 1-i n 1 m 1}$, and the protein produced should be free of unwanted peptide at the $\mathrm{N}$-terminus because there is no other ATG triplet in the $5^{\prime}$ UTR in any possible frames. The $\mathrm{D}$-amino acid inducible gene 

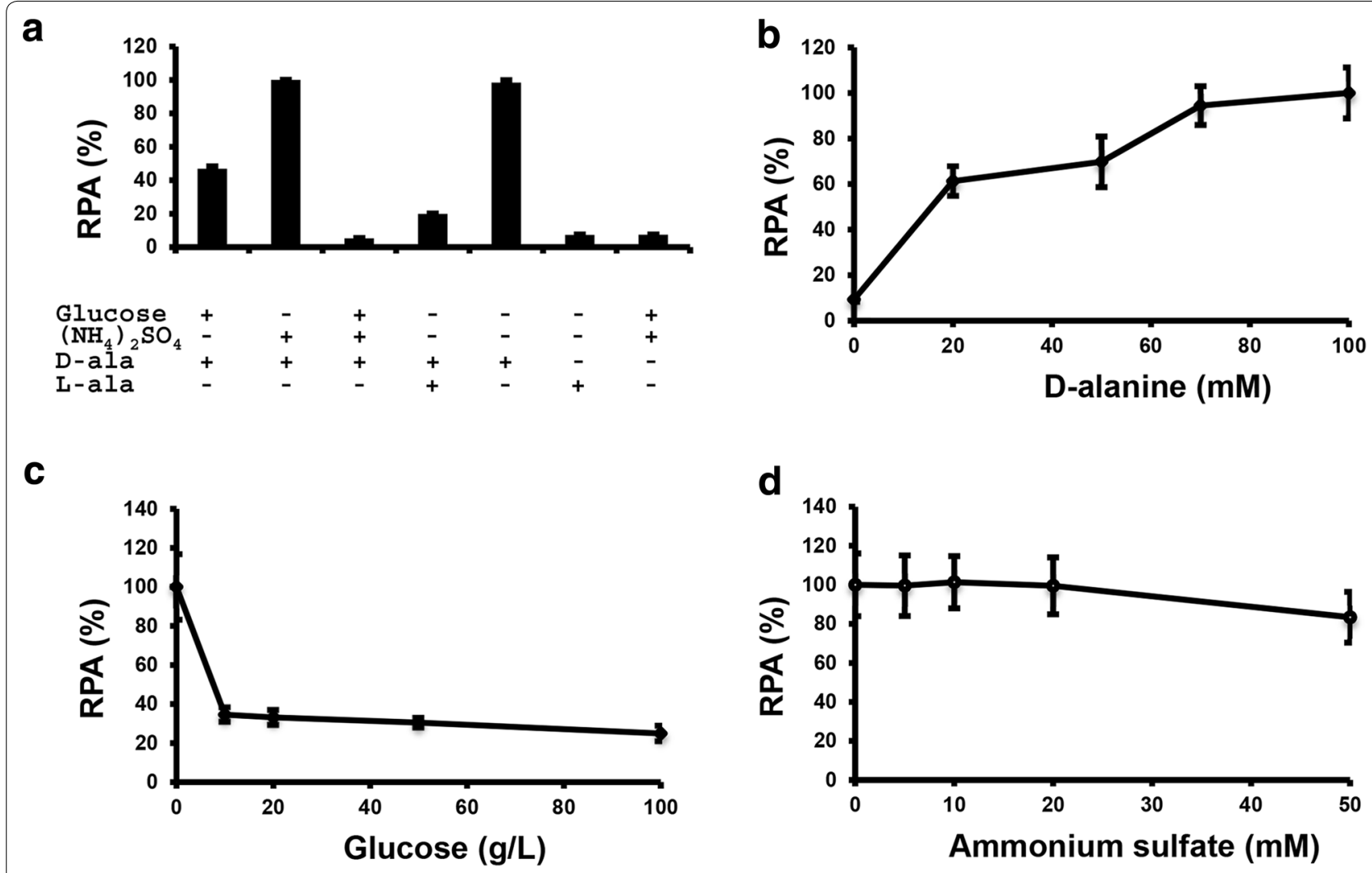

e
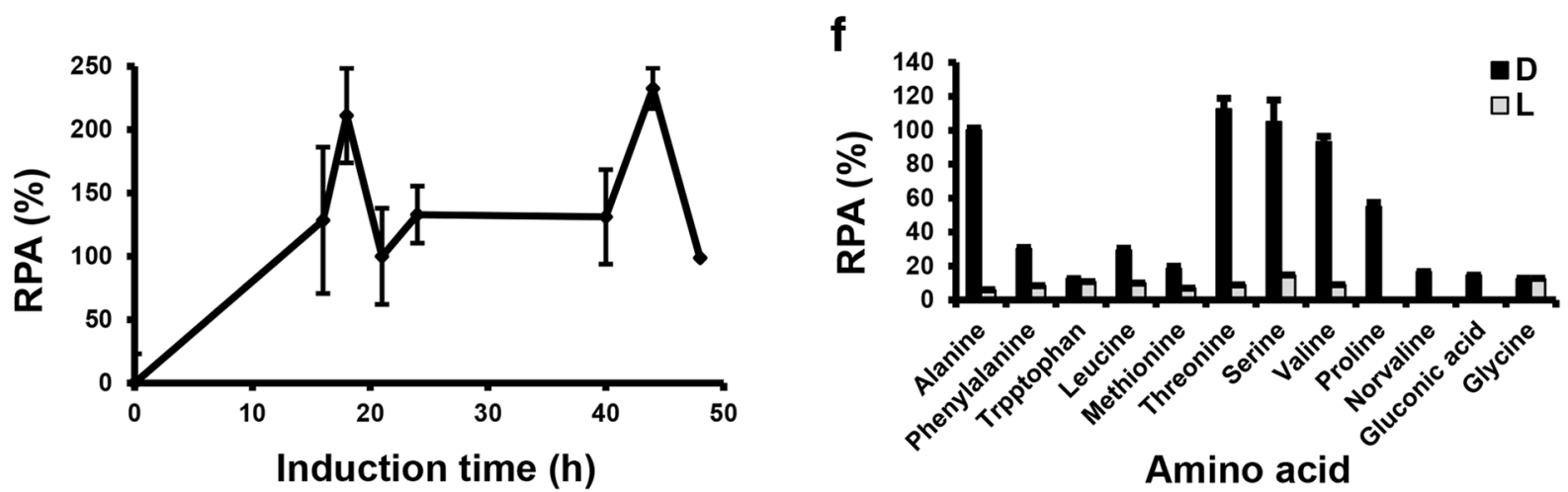

Fig. 8 Effects of carbon and nitrogen sources on DAO1 promoter activity. All assays were done in triplicates with a luciferase reporter strain containing the 2.2-kb $P_{D A O 1-i n 1}$ fused to RtLUC2 : $T_{355}$ and knocked in at CAR2 locus. a Effect of carbon and nitrogen sources. Cells were cultured for $21 \mathrm{~h}$ in MinABs supplemented with the designated carbon and nitrogen sources. G glucose (10 g/L), AS ammonium sulfate (70 mM), D-ala D-alanine (70 mM), L-ala L-alanine (70 mM). b Effects of different concentrations of D-alanine. $10 \mathrm{~g} / \mathrm{L}$ glucose and different concentrations of D-alanine were supplemented to the basal medium MinABs. c Effects of different concentrations of glucose. 70 mM D-alanine and different concentration of D-alanine were supplemented to basal medium MinABs. d Effects of different concentrations of ammonium sulfate. $10 \mathrm{~g} / \mathrm{L}$ glucose, $70 \mathrm{mM}$-alanine and different concentrations of ammonium sulfate were supplemented to basal medium MinABs. e Time course of promoter activities. 70 mM $D$-alanine was used as the sole carbon and nitrogen source. $\mathbf{f}$ Effects of different D-amino acids as the inducer. D and $L$ represents $D$ - and L-alanine, respectively

expression system can be enhanced by using a $D A O 1$ null mutant $(\Delta$ daole $)$, which allowed much stronger induction in media with carbon source and/or nitrogen source (Fig. 9). With the inactivation of degradation system for the $\mathrm{D}$-amino acid inducer, $\Delta$ daole strain allowed significantly improved gene induction with much lower concentration of inducer needed and thus, reduced cost for its applications. We expect similar inducible gene 
a

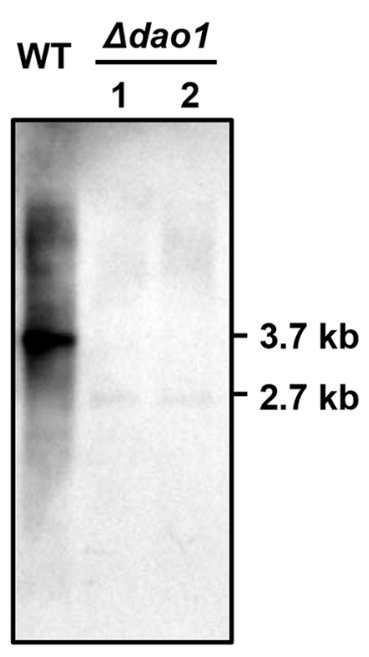

C

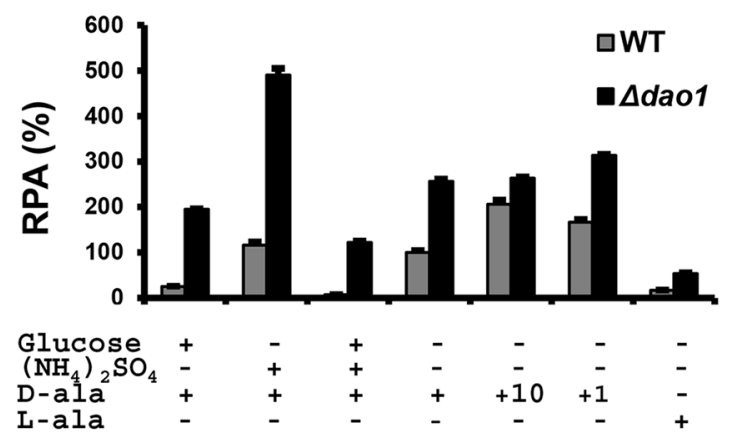

b

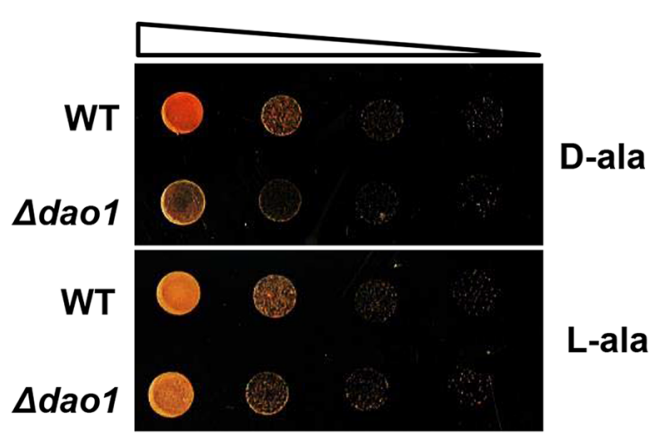

d

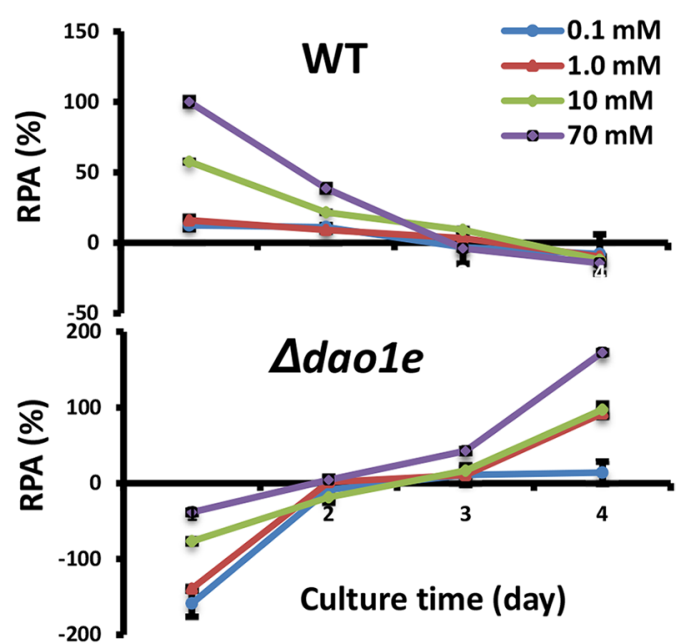

Fig. 9 Effects of DAO1 gene deletion. a Southern blot analysis of DAO1 knockout mutants. Genomic DNA (2 $\mu \mathrm{g})$ was digested with Pstl and hybridized against the digoxigenin-labeled probe of DAO1R (Probe 2 in Fig. 2a). b Growth of DAO1 null mutant and WT in YNB medium with D-alanine and L-alanine as the sole carbon source. c Response of $2.2 \mathrm{~kb} \mathrm{P}_{D A O}$ in 1 in WT and DAO1 knockout mutant ( $\triangle$ dao 1 e) in MinABs supplemented with glucose $(10 \mathrm{~g} / \mathrm{L})$, ammonium sulfate $(70 \mathrm{mM})$, L-alanine $(\mathrm{L}-\mathrm{ala}, 70 \mathrm{mM})$. (+) indicates $70 \mathrm{mM}$ D-alanine while other concentrations used are marked with $+10(\mathrm{mM})$ and $+1(\mathrm{mM})$, respectively. $\mathbf{d}$ Time course of $2.2 \mathrm{~kb} \mathrm{P}_{\text {DAOT-in } 1}$ activity in WT and $\triangle$ daole strains. Strains were cultured in MinABs medium supplemented with various concentrations of D-alanine indicated

expression system can be created for other fungi because Dao proteins are highly conserved. The D-amino acid inducible gene expression system reported here should find applications metabolic pathways, genome editing and enzyme expression in Rhodosporidium and Rhodotorula species and beyond.

CAAT box, TATA box and CT box are considered the "core promoter elements" of fungal promoters [30]. The GCCCAATCA motif (-647 to -638) shares high similarity to CAAT box consensus sequence (GCc/tCAATCT) found in eukaryotic promoter although it is located more distal to the transcriptional start point (tsp) than most fungal promoters. Similar to many genes of filamentous fungi [30], a CT-rich motif (CTCTCTTTCGCTCTT) is located immediately upstream of transcriptional start point of DAO1 mRNA (Fig. 5 and Additional file 1). On the other hand, no TATA box in the proximity of tsp nor canonical polyadenylation signal (AATAAA) near the transcriptional termination site was found. Similarly to DAO1, R. toruloides GPD1, KU70 and KU80 genes also contain no TATA box or canonical polyadenylation signal $[6,7]$. Because Rhodosporidium and Rhodotorula genomes are amongst the most GC-rich known, with more than $62 \%$ CG content [31], it is intriguing how 
cis-acting elements and the corresponding transcription factors have been evolved during the evolution of these organisms. To the best of our knowledge, DRE1 and IES1 are the first functionally verified cis-acting elements reported in Pucciniomycotina to date. The location of an enhancing element in intron 1 was unexpected. Recently, intron 1 of Yarrowia lipolytica FBA1 gene was also reported to strongly enhance gene expression [32]. These suggest that intronic gene transcriptional enhancer may be more common than we currently know. The positive (IES1) and negative (DRE1) cis-acting elements identified here will be useful for engineering promoters with lower basal transcriptional level and stronger mRNA transcriptional activity using strategies that have been extensively applied in other eukaryotic organisms [33-35].

We noticed the basal expression level under noninducing conditions (examples see L-alanine in Figs. 6b, 8a) remained high. It is possible that alanine racemase (EC 5.1.1.1, ALR), which converts L-alanine to D-alanine, played a role because a putative homolog of Schizosaccharomyces pombe alanine racemase (GenBank acc. no. AL023590) [34] could be found in the $R$. toruloides genome. This gene could be a target for further improvement of D-amino acid inducible expression in Rhodosporidium and Rhodotorula.

\section{Conclusion}

The intron 1 containing DAO1 promoter coupled with a $D A O 1$ null mutant makes an efficient and tight D-amino acid-inducible gene expression system in Rhodosporidium and Rhodotorula genera. The system will be a valuable tool for metabolic engineering and enzyme expression in these yeast hosts.

\section{Methods}

\section{Strains, media, and culture conditions}

R. toruloides strain ATCC 10657 was obtained from ATCC (USA). $\triangle$ ku70e is a derivative of KU70 knockout mutant with hygromycin selection cassette removed by activation of Cre recombinase and allows highly efficient gene deletion by homologous recombination [7]. R. toruloides strains were cultured at $28{ }^{\circ} \mathrm{C}$ in YPD broth $(1 \%$ yeast extract, $2 \%$ peptone, $2 \%$ glucose, w/v) or on YPD agar. A. tumefaciens strain AGL2 [36] was cultured at $28{ }^{\circ} \mathrm{C}$ in either $2 \mathrm{YT}$ broth or $2 \mathrm{YT}$ agar medium $(1.6 \%$ tryptone, $1 \%$ yeast extract, $0.5 \% \mathrm{NaCl})$. Escherichia coli XL1-Blue was cultured in Luria-Bertani (LB) broth or on LB agar and used for routine DNA manipulations.

For gene induction studies, chemically-defined minimal medium MinAB [37] without carbon source and nitrogen source, named as MinABs here, was used as the basal medium, which was supplemented with carbon source and nitrogen source when desired. Unless indicated otherwise, cells were cultured in $250 \mathrm{ml}$ flasks or $50 \mathrm{ml}$ Falcon tubes with agitation $(250 \mathrm{rpm})$ at $28^{\circ} \mathrm{C}$. For lipid accumulation, medium Y4 containing $100 \mathrm{~g} / \mathrm{L}$ glucose, $15.7 \mathrm{~g} / \mathrm{L}$ peptone, $15.7 \mathrm{~g} / \mathrm{L}$ yeast extract, $12 \mathrm{~g} / \mathrm{L}$ $(\mathrm{NH} 4)_{2} \mathrm{SO}_{4}, 1 \mathrm{~g} / \mathrm{L} \mathrm{KH}_{2} \mathrm{PO}_{4}, 1.5 \mathrm{~g} / \mathrm{L} \mathrm{MgSO}_{4} \cdot 7 \mathrm{H} 2 \mathrm{O}(\mathrm{pH} 5.5)$ was used [24].

\section{Plasmid constructs}

Oligonucleotides used are listed in Table 1. All DNA restriction and modification enzymes were sourced from New England Biolabs (NEB, USA). Plasmid pKCL2 (Fig. 5a) is a pPZP200 derivative [38] consisting of a hygromycin resistant cassette $\left(\mathrm{P}_{\text {GPD1-3 }}: H P T-3:: \mathrm{T}_{S V 40}\right)$ and a luciferase reporter cassette $\left(\mathrm{P}_{G P D 1}: \operatorname{Rt} L U C 2:: \mathrm{T}_{35 S}\right)$. $\mathrm{P}_{\text {GPD1-3 }}$ and $\mathrm{P}_{\text {GPD1 }}$ are the glyceraldehyde 3-phosphate promoter of $R$. graminis WP1 and $R$. toruloides ATCC 10657, with GenBank accession number of JQ806386 and JN208861, respectively [6]. HPT-3 (JQ806387) and RtLUC2 (KR258785) are the codon-optimized synthetic genes encoding the $E$. coli hygromycin phosphotransferase and firefly luciferase (Luc2, ACH53166.1), respectively [6].

pKCL2 allows efficient site-specific integration of reporter gene cassette at the $C A R 2$ locus (Fig. 5a). To make this, a $2321 \mathrm{~kb}$ genomic DNA fragment of CAR2 (396,844-399,540 nt of scaffold \#18, AEVR02000018) was amplified by PCR using genomic DNA of $R$. toruloides ATCC 10657 as template and oligos Rt079 and C250r as primers. The PCR products were treated with T4 polynucleotide kinase and ligated with the SacI (bluntended)/PmeI-double digested pEX2 plasmid [39] to create the intermediate plasmid pEX2CAR2kc. The $8.6-\mathrm{kb}$ XhoI-linearized and blunt-ended pEX2CAR2kc was ligated with the $\mathrm{P}_{G P D 1-3}:: h p t-3:: \mathrm{T}_{S V 40}-\mathrm{P}_{G P D 1}:$ RtGFP:: $\mathrm{T}_{35 S}$ double gene cassettes obtained by digestion of pRHE33 (Fig. 5b) with EcoRI and $S s p$ I followed by blunt-ending using T4 DNA polymerase in the presence of dNTPs. The RtGFP gene in $\mathrm{pKC} 2$ was replaced with the synthetic $1.7 \mathrm{~kb} N c o I-E c o R V$ fragment of Rt $L U C 2$ to create pKCL2.

The $2.0 \mathrm{~kb}$ upstream region of $D A O 1$ was obtained by PCR amplification using oligos Rt290Sf and Rt309Nr as primers (Table 1), yielding a PCR fragment with $5^{\prime}$ SpeI and $3^{\prime}$ NcoI cutting sites, the latter of which (CCATGG) overlaps with the original predicted translational codon (ATG) of DAO1. The PCR products were double-digested with SpeI and NcoI before inserted into same sites of pKCL2 to create pKCLD1 (Fig. 5b). The $2.2 \mathrm{~kb}$ intron 1-containing promoter $\mathrm{P}_{D A O 1-i n 1}$ was amplified with oligos Rt290Sf and Rt $287 \mathrm{Nr}$ as primers. The SpeI-NcoI treated PCR products of $\mathrm{P}_{D A O 1-i n 1}$ were inserted at the same sites in pKCL2 to create plasmid pKCLD2 (Fig. 5b). $\mathrm{P}_{\text {DAO1-in1 }}$ includes the 108-nt intron 1 and 6-nt exon 2 sequence, with which a 16-aa peptide 
(MHSQKRVVVLGSGVIA) will be added to the N-terminus of any protein expressed (Fig. 5c).

The $2.2 \mathrm{~kb} \mathrm{P}_{\text {DAOIm1-in1 }}$ promoter (Fig. 6a), which has the D-amino acid responsive element 1 (DRE1) deleted, was created by fusion PCR: DNA sequence upstream and downstream of DRE1 was individually amplified using pKCLD2 as the template and oligo pair SFGFPSEQ/ Rt312 and Rt311/35STer as primers, yielding PCR fragments of 2.1 and $1.3 \mathrm{~kb}$ in length, which were used as PCR templates at a molar ratio of 1:1 to make the DRE1deleted 2.2 kb $\mathrm{P}_{\text {DAO1m1-in1 }}$ promoter using oligos Rt290Sf and Rt $287 \mathrm{Nr}$ as primers. After double-digestion with SpeI and NcoI, $\mathrm{P}_{\text {DAOIm1-in1 }}$ fragment was inserted to pKCL2 at the same sites to create pKCLD3 (Fig. 5b). A promoter-less RtLUC2 reporter construct, pKCL20, was made by self-ligation of SpeI-NcoI digested and bluntended pKCL2.

Truncated promoters of approximately $1.7 \mathrm{~kb}\left(\mathrm{P}_{\text {DAO1m2- }}\right.$ in1 $), 1.2 \mathrm{~kb}\left(\mathrm{P}_{\text {DAO1m3-in1 } 1}\right), 1.0 \mathrm{~kb}\left(\mathrm{P}_{\text {DAO1m4-in } 1}\right), 0.7 \mathrm{~kb}\left(\mathrm{P}_{\text {DAO1m5- }}\right.$ in1 $)$ and $0.4 \mathrm{~kb}\left(\mathrm{P}_{\text {DAO1m6-in } 1}\right)$ in length were amplified using oligo Rt287Nr as reverse primer and Rt315S, Rt314S, Rt120S, Rt313S and Rt117S as forward primer, respectively (Table 1). All PCR products were double-digested with SpeI and $\mathrm{NcoI}$ and followed by insertion to pKCL2 at the same sites to create plasmid pKCLD4 to pKCLD8, respectively (Figs. 5b, 6).

Promoter $\mathrm{P}_{\text {DAOIm5-in1m1 }}$ contains the ATG to ATC point mutation at the translation initiation codon and "TTGGCCTGA" to "TTGCCATGG mutations in exon 2 (Fig. 5c). This shifts the translation initiation codon to exon 2, with the translation of first 16-aa peptide of Dao1 abolished. Oligo pair SFGFPSEQ/Rt327r and Rt328f/ LUC2U were used amplify the 0.8 and $0.4 \mathrm{~kb}$ DNA mutant fragments, which were fused by PCR using oligos of Rt313S and Rt287Nr. The resultant $0.7 \mathrm{~kb}$ PCR product was digested with SpeI-NcoI and inserted to pKCL2 at the same sites to make pKCLD71. Similarly, oligo pair SFGFPSEQ/Rt329r was used to amplify the $0.8 \mathrm{~kb}$ upstream DNA fragment that was shared for $\mathrm{P}_{\text {DAO1m5- }}$ in1m2 to $\mathrm{P}_{D A O 1 m 5-i n 1 m 8}$ while the downstream fragment was amplified using the common reverse primer Luc2U coupled with forward primer Rt330f, Rt331f, Rt334f, Rt335f, Rt336f, Rt337f and Rt338f, respectively. The above PCR fragments were fused by PCR using oligos Rt313S and $\mathrm{Rt} 287 \mathrm{Nr}$ followed by double digestion with SpeI and $\mathrm{NcoI}$ before insertion into pKCL2 to create plasmid pKCLD72 to pKCLD79, respectively (Fig. 5b).

$D A O 1$ knockout vector pKODAO1 was created first by amplifying the $5^{\prime}$ and $3^{\prime}$ flanking sequence $(0.6 \mathrm{~kb}$ each) using oligo pair DAO1L-Sf/DAO1L-Br and DAO1RHf/DAO1R-Str as the primers. The PCR fragments were assembled by four-fragment ligation, consisting of SacI/BamHI-cut $5^{\prime}$ homology arm, HindIII/StuI-cut $3^{\prime}$ homology arm, HindIII/BamHI cut hygromycin resistance cassette obtained from pDX1PgpdRhptR [7] and SacI/PmeI-cut dephosphorylated pEX2tk [39].

\section{Extraction of genomic DNA and total RNA}

Genomic DNA was extracted using the MasterPure-Yeast DNA and RNA Purification Kits, respectively (Epicenter, USA). The concentrations of DNA or RNA samples were determined with NanoDrop ${ }^{\circledR}$ ND-1000 Spectrophotometer (Nanodrop Technologies, USA) and the integrity of the extracted nucleic acids were checked by agarose gel electrophoresis. DNA and RNA concentrations of the samples were typically $100-1000 \mathrm{ng} / \mu \mathrm{L}$.

\section{Rapid amplification of CDNA ends (RACE)}

The $5^{\prime}$ and $3^{\prime}$ end of DAO1 cDNA sequences were obtained by $5^{\prime}$ RACE and $3^{\prime}$ RACE using BD SMARTer ${ }^{\text {TM }}$ RACE cDNA Amplification Kit (Clontech, USA) according to the manufacturer's instruction. Oligos DAO1U and DAO1L (Table 1) were used as the specific primer for 5' RACE and 3' RACE, respectively. The full-length cDNA was cloned by RT-PCR using DNase I-treated total RNA as the template and Rt332 and Rt333 as the primers.

\section{Southern blot analysis}

Genomic DNA $(5 \mu \mathrm{g})$ was digested with restriction enzymes, separated in $0.8 \%$ agarose gel and blotted to Hybond $\mathrm{N}^{+}$membrane (GE Healthcare Life Sciences, USA). DNA probes were labeled with DIG High Prime DNA Labeling and Southern hybridization and detection were performed according to manufacturer's instruction (Roche Diagnostics, USA).

\section{Quantitative reverse transcription PCR (qRT-PCR)}

Total RNA was treated with DNase I (Roche Diagnostics, Germany) followed by precipitation with ethanol. cDNA was synthesized using the iScript ${ }^{\mathrm{TM}}$ Reverse Transcription Supermix for reverse transcription (Bio-Rad, USA) and real-time PCR was conducted in ABI PRISM 7900HT Sequence Detection System (Life Technologies, USA) using the ABI SYBR ${ }^{\circledR}$ Select Master Mix (Life Technologies, USA). Real-time PCR conditions were as followed: an initial $50{ }^{\circ} \mathrm{C}$ for $2 \mathrm{~min}$ and $95{ }^{\circ} \mathrm{C}$ denaturation for $10 \mathrm{~min}$ followed with 40 cycles of denaturation at $95{ }^{\circ} \mathrm{C}$ for $15 \mathrm{~s}$, annealing and amplification at $60^{\circ} \mathrm{C}$ for 1 min. qRT-PCR analysis was done with biological triplicates. Data was acquired using the software SDS 2.4 (Life Technologies, USA) and the relative gene expression levels were calculated against the reference gene ACT1 (GenBank accession number KR138696) using the $2^{-\Delta \Delta C t}$ method facilitated with the RQ Manager software v1.2.1 (Life Technologies USA). 


\section{Analysis of promoter activity}

Binary T-DNA vectors were electroporated into Agrobacterium tumefaciens AGL2 and A. tumefaciens-mediated transformation (ATMT) of $R$. toruloides was performed as previously described [6]. Strains bearing the inserted T-DNA at the CAR2 locus were identified by the albino phenotype followed by confirmation with Southern blotting.

Luciferase reporter strains were cultured in YPD broth to mid-exponential phase. Cells were washed twice with water and inoculated to various media at an optical density $\left(\mathrm{OD}_{600}\right)$ of 0.5 and cultured at $30{ }^{\circ} \mathrm{C}$ with agitation $(250 \mathrm{rpm})$. Cell cultures $(2 \mathrm{~mL})$ were harvested, washed and re-suspended in PBS buffer supplemented with $1 \mathrm{mM}$ DTT, $3 \mathrm{mM} \beta$-ME and $1 \mathrm{mM}$ PMSF (pH7.4). After addition of equal volume of glass beads (0.5 $\mathrm{mm}$ in diameter, Sigma-Aldrich, USA), cells were ruptured in a bead beater (FastPrep-24 $4^{\mathrm{TM}} 5 \mathrm{G}$, MP Biomedicals, Solon, OH, USA) with two cycles of beating (45 s) and cooling in ice-water bath (5 min). After centrifugation $\left(4^{\circ} \mathrm{C}, 14,000 \mathrm{rpm}\right.$ for $\left.15 \mathrm{~min}\right)$, the supernatants were collected as crude enzyme preparation and total protein contents were determined by the Bradfort method [40] using Quick Start ${ }^{\mathrm{TM}}$ Bradford Protein Assay Kit (Bio-Rad, USA) with bovine serum albumin (BSA) as the standard.

Luciferase activity was determined by bioluminescence using Luciferase Assay System (Promega, USA). All data were measured and acquired with the Infinite M200 plate reader coupled with the iCycler software (version 3.0) (Tecan, Austria). Protein concentrations were measured at OD of $595 \mathrm{~nm}$ with $5 \mu \mathrm{L}$ of samples or protein standard, which were mixed with $250 \mu \mathrm{l} 1 \times$ dye reagent (Bio-Rad) and loaded to wells in a 96-well flat-bottom transparent plate (Nunc, Denmark). Luminescent values were measured after mixing $10 \mu \mathrm{L}$ of samples with $100 \mu \mathrm{L}$ of Luciferase Assay Reagent (Promega) in wells of a FluoroNunc 96-well plate (Thermo Fisher Scientific, Germany). The relative promoter activity (RPA) was calculated as followed: $\mathrm{RPA}=\left[\left(\mathrm{L}_{\mathrm{T}}-\mathrm{L}_{\mathrm{BLK}}\right) / \mathrm{P}_{\mathrm{T}}-\left(\mathrm{L}_{\mathrm{N}}-\mathrm{L}_{\mathrm{BLK}}\right) /\right.$ $\left.\mathrm{P}_{\mathrm{N}}\right] /\left[\left(\mathrm{L}_{\mathrm{P}}-\mathrm{L}_{\mathrm{BLK}}\right) / \mathrm{P}_{\mathrm{P}}-\left(\mathrm{L}_{\mathrm{N}}-\mathrm{L}_{\mathrm{BLK}}\right) / \mathrm{P}_{\mathrm{N}}\right]$, where $\mathrm{L}_{\mathrm{T}}, \mathrm{L}_{\mathrm{N}}, \mathrm{L}_{\mathrm{P}}$ and $L_{B L K}$ represents the bioluminescent value of target promoter, promoter-less, full-length promoter and PBS buffer blank, respectively, and $\mathrm{P}_{\mathrm{T}}, \mathrm{P}_{\mathrm{P}}$ and $\mathrm{P}_{\mathrm{N}}$ represents the protein concentration of the enzyme preparation derived from strain with the target promoter, full-length promoter and promoter less, respectively.

\section{GenBank accession numbers}

All DAO1 genes together with their $2 \mathrm{~kb}$ upstream sequences from Basidiomycotina, i.e. Rhodosporidium toruloides ATCC 10657, Rhodotorula glutinis ATCC 204091, Rhodotorula graminis WP1, Rhodosporidium toruloides MTCC 457, Rhodosporidium toruloides NP11, Sporobolomyces reseus, Puccinia tritartica, Puccinia graminis, Melampsora laricis-populina, Rhodotorula minuta, Sporobolomyces linderae, Ustilago maydis, Sporisorium reilianum, were deposited to GenBank under accession numbers KR183638-183695, respectively (Additional file 1). Actin encoding gene (ACT1) of R. glutinis ATCC 204091 is under GenBank accession number KR183696 (Additional file 5). The synthetic RtLUC2 gene (GenBank accession number KR258785) was made by Genscript, USA. All sequences are available in Additional files $4,5,6$.

\section{Additional file}

Additional file 1. Structure of R. toruloides DAO1 gene. Nucleotide positions are defined from the translational start codon "ATG" (in which the position of "A" is +1 ). Protein positions are labeled with the prefix " $P$ ". The translational start codon within Ncol site (CCATGG) in the intron 1-containing promoters are and the ATG to ATC mutation are boxed. Exons are shown in capital letters and introns are in lowercase italics; the putative CAAT box is highlighted in grey; DRE1, ct box and IES1 are indicated with shaded text. The putative coenzyme binding consensus sequence (GXGXXG, where "X" is any amino acid) is underlined; the dimerization loop is double underlined; the amino acid residues $\mathrm{H}$-bonded to the flavin O-2 atom (YQ) are in bold and italics; TG repeats upstream of the polyA site are highlighted in grey; the residues interacting with the -carboxy and -amino groups of the substrate $\left(Y_{223}, Y_{238}\right.$ and $\left.R_{285}\right)$ are boxed and highlighted in grey; the C-terminus peroxisomal targeting signal $(\mathrm{SKL})$ is highlighted in grey. Abbreviations: ct box: pyrimidine-rich region; tsp: transcriptional start point; PolyA site: polyadenylation site.

Additional file 2. Basidiomycetous DAO1 genes and phylogenic analysis of their proteins. (a) Schematic diagrams of DAO1 genes from Pucciniomycotina and Ustilagiomycotina subphyla. Introns are shown in white bars. (b) Phylogenetic tree analysis of putative D-amino acid oxidases from Pucciniomycotina and Ustilagiomycotina subphyla. The phylogenic tree was constructed by MEGA version 6 program (http://www.megasoftware. net/) using Neighbor-Joining algorithm and tested by Bootstrapping. The DAO1 sequences are listed in GenBank under accession numbers KR183638-183695

Additional file 3. Residual carbon and nitrogen sources during lipid accumulation. R. toruloides was cultured in the lipid accumulation medium Y4 [23] with some modifications (see Materials and Methods) for 5 days. (a) Residual ammonium concentration in cell culture. (b) Residual glucose concentration in cell culture.

Additional file 4. Codon usage in R. toruloides DAO1.

Additional file 5. DAO1 gene sequences (Submitted GenBank sequence record ahead of release). (a) List of sequence ID, organisms and GenBank accession numbers of DAO1 and ACT1 genes. (b) Genome sequences of DAO1 genes (start at -2000). (c) Protein sequences of Dao1.

Additional file 6. Sequence of the mutation promoter $\mathrm{P}_{\text {DAOIm5-in } 1 \mathrm{~m} 1}$ (renamed as $\mathrm{P}_{\text {DAOIint }}$ ).

\section{Abbreviations}

ATCC: American Type Culture Collection, USA; DAO1: D-amino acid oxidase gene; GPD1: glyceraldehyde 3-phosphate dehydrogenase gene; RtGFP: a commercially synthesized green fluorescent protein (eGFP) gene according to the codon bias of $R$. toruloides; RtLUC2: a commercially synthesized luciferase (LuC2) encoding gene according to the codon bias of R. toruloides; CAR2: bifunctional enzyme phytoene synthase and lycopene cyclase encoding gene; BLAST: Basic Local Alignment Search Tool (National Library of Medicine, National Institutes of Health, USA); FAD: flavin adenine dinucleotide; MEME 
server: motif-based sequence analysis tools (National Institutes of Health USA); DRE1: D-amino acid responsive element 1; ISE1: intronic enhancer sequence 1.

\section{Authors' contributions}

$L J$ and $Y L$ conceived experiments and drafted the manuscript. $Y L, C M J K$ and STN participated in experiments and data analysis. All the authors have read and approved the final manuscript.

\section{Authors' information}

$\mathrm{LJ}$ is the head of the laboratory and a program Director of Temasek Life Sciences Laboratory. YL is a Research Associate; CMJK is a Research Officer and STN is an Assistant Research Officer at the Temasek Life Sciences Laboratory, 1 Research Link, NUS, Singapore 117604.

\section{Acknowledgements}

This work was financially supported by Singapore National Research Fundation CRP-8-2011-02, Singapore Economic Development Board and Temasek Trust.

\section{Competing interests}

The authors declare that they have no competing interests. Temasek Life Sciences Laboratory has an interest in developing Rhodosporidium toruloides as an industrial biotechnology platform.

Received: 21 July 2015 Accepted: 7 October 2015

Published online: 26 October 2015

\section{References}

1. Sampaio JP, Gadanho M, Bauer R, Weiß M. Taxonomic studies in the Microbotryomycetidae: Leucosporidium golubevii sp. nov., Leucosporidiella gen. nov. and the new orders Leucosporidiales and Sporidiobolales. Mycol Prog. 2003;2:53-68.

2. Yamazaki M, Komagata K. Taxonomic significance of electrophoretic comparison of enzymes in the genera Rhodotorula and Rhodosporidium. Int J Syst Bacteriol. 1981;31:361-81.

3. Zhao X, Wu S, Hu C, Wang Q, Hua Y, Zhao ZK. Lipid production from Jerusalem artichoke by Rhodosporidium toruloides Y4. J Ind Microbiol Biotechnol. 2010;37:581-5.

4. Liu H, Zhao X, Wang F, Li Y, Jiang X, Ye M, Zhao ZK, Zou H. Comparative proteomic analysis of Rhodosporidium toruloides during lipid accumulation. Yeast. 2009;26:553-66.

5. Turcotte G, Kosaric N. Biosynthesis of lipids by Rhodosporidium toruloides ATCC 10788. J Biotechnol. 1988;8:221-37.

6. Liu Y, Koh CM, Sun L, Hlaing MM, Du M, Peng N, Ji L. Characterization of glyceraldehyde-3-phosphate dehydrogenase gene RtGPD1 and development of genetic transformation method by dominant selection in oleaginous yeast Rhodosporidium toruloides. Appl Microbiol Biotechnol. 2013;97:719-29.

7. Koh CM, Liu Y, Du M, Ji L. Molecular characterization of KU70 and KU80 homologues and exploitation of a KU70-deficient mutant for improving gene deletion frequency in Rhodosporidium toruloides. BMC Microbiol. 2014;14:50.

8. Lin X, Wang Y, Zhang S, Zhu Z, Zhou YJ, Yang F, Sun W, Wang X, Zhao ZK. Functional integration of multiple genes into the genome of the oleaginous yeast Rhodosporidium toruloides. FEMS Yeast Res. 2014;14:547-55.

9. Abbott EP, laniri G, Castoria R, Idnurm A. Overcoming recalcitrant transformation and gene manipulation in Pucciniomycotina yeasts. Appl Microbiol Biotechnol. 2013;97:283-95.

10. Pollegioni L, Piubelli L, Sacchi S, Pilone MS, Molla G. Physiological functions of D-amino acid oxidases: from yeast to humans. Cell Mol Life Sci. 2007:64:1373-94.

11. Pollegioni L, Molla G, Sacchi S, Rosini E, Verga R, Pilone MS. Properties and applications of microbial D-amino acid oxidases: current state and perspectives. Appl Microbiol Biotechnol. 2008;78:1-16.

12. De Duve C, Baudhuin P. Peroxisomes (microbodies and related particles). Physiol Rev. 1966:46:323-57.
13. Fukui S, Kawamoto S, Yasuhara S, Tanaka A, Osumi M. Microbody of methanol-grown yeasts. Localization of catalase and flavin-dependent alcohol oxidase in the isolated microbody. Eur J Biochem. 1975;59:561-6.

14. Simonetta MP, Vanoni MA, Curti B. D-Amino acid oxidase activity in the yeast Rhodotorula gracilis. FEMS Microbiol Lett. 1982;15:27-31.

15. Molla G, Motteran L, Piubelli L, Pilone MS, Pollegioni L. Regulation of D-amino acid oxidase expression in the yeast Rhodotorula gracilis. Yeast. 2003;20:1061-9.

16. Paul D, Magbanua Z, Arick M, 2nd, French T, Bridges SM, Burgess SC, Lawrence $M L$. Genome sequence of the oleaginous yeast Rhodotorula glutinis ATCC 204091. Genome Announc. 2014;2:1-2

17. Pollegioni L, Molla G, Campaner S, Martegani E, Pilone MS. Cloning, sequencing and expression in E. coli of a D-amino acid oxidase CDNA from Rhodotorula gracilis active on cephalosporin C. J Biotechnol. 1997;58:115-23.

18. Kozak M. Compilation and analysis of sequences upstream from the translational start site in eukaryotic mRNAs. Nucleic Acids Res. 1984;12:857-72.

19. Wierenga RK, Drenth J, Schulz GE, Huber R. Comparison of the threedimensional protein and nucleotide structure of the FAD-binding domain of $p$-hydroxybenzoate hydroxylase with the FAD-as well as NADPH-binding domains of glutathione reductase. J Mol Biol. 1983;167:725-39.

20. Faotto L, Pollegioni L, Ceciliani F, Ronchi S, Pilone MS. The primary structure of D-amino acid oxidase from Rhodotorula gracilis. Biotechnol Lett. 1995;17:193-8.

21. Perotti ME, Pollegioni L, Pilone MS. Expression of D-amino acid oxidase in Rhodotorula gracilis under induction conditions: a biochemical and cytochemical study. Eur J Cell Biol. 1991;55:104-13.

22. Teixeira MC, Monteiro PT, Guerreiro JF, Goncalves JP, Mira NP, dos Santos SC, Cabrito TR, Palma M, Costa C, Francisco AP, et al. The YEASTRACT database: an upgraded information system for the analysis of gene and genomic transcription regulation in Saccharomyces cerevisiae. Nucleic Acids Res. 2014:42:D161-6.

23. Simonetta MP, Vanoni MA, Casalin P. Purification and properties of d-amino-acid oxidase, an inducible flavoenzyme from Rhodotorula gracilis. Biochim Biophys Acta. 1987;914:136-42.

24. Li Y, Zhao Z, Bai F. High-density cultivation of oleaginous yeast Rhodosporidium toruloides $Y 4$ in fed-batch culture. Enzyme Microbial Technol. 2007;41:312-7.

25. Weinhandl K, Winkler M, Glieder A, Camattari A. Carbon source dependent promoters in yeasts. Microb Cell Fact. 2014;13:5

26. Bottin A, Kamper J, Kahmann R. Isolation of a carbon source-regulated gene from Ustilago maydis. Mol Gen Genet. 1996;253:342-52.

27. Fuchs U, Manns I, Steinberg G. Microtubules are dispensable for the initial pathogenic development but required for long-distance hyphal growth in the corn smut fungus Ustilago maydis. Mol Biol Cell. 2005;16:2746-58.

28. Ro DK, Paradise EM, Ouellet M, Fisher KJ, Newman KL, Ndungu JM, Ho KA, Eachus RA, Ham TS, Kirby J, et al. Production of the antimalarial drug precursor artemisinic acid in engineered yeast. Nature. 2006;440:940-3.

29. Kozak M. Pushing the limits of the scanning mechanism for initiation of translation. Gene. 2002;299:1-34.

30. Unkles S. Gene organization in industrial filamentous fungi. In: Kinghorn JR, Turner G (eds) Applied molecular genetics of filamentous fungi. Glasgow: Blackie Academic and Professional; 1992. p. 28-53.

31. Kumar S, Kushwaha H, Bachhawat AK, Raghava GPS, Ganesan K. Genome sequence of the oleaginous red yeast Rhodosporidium toruloides MTCC 457. Eukaryot Cell. 2012;11:1083-4.

32. Hong SP, Seip J, Walters-Pollak D, Rupert R, Jackson R, Xue Z, Zhu Q. Engineering Yarrowia lipolytica to express secretory invertase with strong FBA $1_{\mathbb{N}}$ promoter. Yeast. 2011;29:59-72.

33. Soda K, Esaki N. Pyridoxal enzymes acting on D-amino acids. Pure Appl Chem. 1994;66:709-14.

34. Uo T, Yoshimura T, Tanaka N, Takegawa K, Esaki N. Functional characterization of alanine racemase from Schizosaccharomyces pombe: a eucaryotic counterpart to bacterial alanine racemase. J Bacteriol. 2001;183:2226-33.

35. Meinhardt LW, Costa GG, Thomazella DP, Teixeira PJ, Carazzolle MF, Schuster SC, Carlson JE, Guiltinan MJ, Mieczkowski P, Farmer A, et al. Genome and secretome analysis of the hemibiotrophic fungal pathogen, Moniliophthora roreri, which causes frosty pod rot disease of cacao: mechanisms of the biotrophic and necrotrophic phases. BMC Genom. 2014;15:164. 
36. Cai L, Sun L, Fu L, Ji L. Media compositions, selection methods and agrobacterium strains for transformation of plants. Google Patents;2009.

37. Watson B, Currier TC, Gordon MP, Chilton MD, Nester EW. Plasmid required for virulence of Agrobacterium tumefaciens. J Bacteriol. 1975;123:255-64.

38. Lee LY, Gelvin SB. T-DNA binary vectors and systems. Plant Physiol. 2008;146:325-32

39. Liu Y, Koh CM, Sun L, Ji L. Tartronate semialdehyde reductase defines a novel rate-limiting step in assimilation and bioconversion of glycerol in Ustilago maydis. PLoS One. 2011;6:e16438.
40. Bradford MM. A rapid and sensitive method for the quantitation of microgram quantities of protein utilizing the principle of protein-dye binding. Anal Biochem. 1976;72:248-54.

41. Arakawa H, Lodygin D, Buerstedde JM. Mutant loxP vectors for selectable marker recycle and conditional knock-outs. BMC Biotechnol. 2001;1:7.

\section{Submit your next manuscript to BioMed Central} and take full advantage of:

- Convenient online submission

- Thorough peer review

- No space constraints or color figure charges

- Immediate publication on acceptance

- Inclusion in PubMed, CAS, Scopus and Google Scholar

- Research which is freely available for redistribution

Submit your manuscript at

www.biomedcentral.com/submit

() BioMed Central 